\title{
Numerical Simulation of the Effect of Stress on the Seepage of Fractured Rock Mass
}

\author{
Liang Shiwei $\mathbb{C}^{1,2}$ Wang Hongmei, ${ }^{3} \mathrm{Ge} \mathrm{Di}^{2}$ and Zhao Cunqing ${ }^{4}$ \\ ${ }^{1}$ School of Human Settlements and Civil Engineering, Xi'an Jiaotong University, Xi'an 710049, China \\ ${ }^{2}$ Xi'an Kedagaoxin University, Xi'an 710109, China \\ ${ }^{3} X i$ 'an Research Institute of China Coal Technology and Engineering Group Co., Ltd., Xi'an 710054, China \\ ${ }^{4}$ Gansu Lanjin Civil Explosion High-Tech Co., Ltd., Lanzhou 730000, China
}

Correspondence should be addressed to Liang Shiwei; 176032237@qq.com

Received 9 May 2021; Accepted 16 June 2021; Published 9 July 2021

Academic Editor: Yu Wang

Copyright (c) 2021 Liang Shiwei et al. This is an open access article distributed under the Creative Commons Attribution License, which permits unrestricted use, distribution, and reproduction in any medium, provided the original work is properly cited.

In our country, the Yellow River Basin ecological protection and development are put forward under the background of high quality. Among the 14 large-scale coal bases in our country, 9 coal bases are located in the Yellow River Basin, and the ShenfuDongsheng Coalfield, which is currently the largest under development, is located here. The region is in the process of coal mining, and the movement of overlying strata will cause the stress redistribution and coal seam in overlying aquifers also due to the effect of pore water pressure along the seepage of rock fracture and damage of overlying aquifer, so in the same formation, stress and the coupled action of seepage flow will produce mutual influence. This article through the early stage of the theoretical results discussed the application of numerical simulation method for simulating 2301 face, and the effect of stress on seepage is concluded. It is proved that the numerical simulation analysis has an important reference value for the coupling problem of stress and seepage. At the same time, the protective mining of aquifers is the basic condition for the surface ecological protection of the area, and it also provides a theoretical basis for the restoration of the ecological environment in the coal mining areas of the Yellow River Basin.

\section{Introduction}

China's Yellow River Basin is rich in coal resources; nine of the 14 large coal bases in our country coal base distribution are in the China Yellow River Basin's many Dongsheng Coalfields which are located in the western Inner Mongolia, and the development of one of the biggest piece of coal is in the northern Shanxi Province, which has simple mining geological conditions; the surface has the salient feature of the fragile ecological environment. In the edge of Maowusu desert and the Loess Plateau, sparse vegetation and wind erosion are serious, and most of the areas covered by thick windblown sand; the main aquifer of quaternary system of Sarah WuSu group is an unconformable contact on the Jurassic bedrock; the aquifer is the survival of the whole region water system; water is very precious, mainly by the surface precipitation to supply; we have a clear understanding that the development of coal should not be at the expense of the destruction of the local ecological environment, especially in the northwest of Yulin and Ordos region; the region is an arid region, there is little rain, wind is big, and the ecological environment is very frail [1-4]. It is well known that the traditional coal mining causes damage of the underground rock mass structure, under the action of mining pressure and the movement of the overburden; the phenomenon such as fracture and overburden belongs to the discontinuous medium rock at the top of the aquifer in discontinuous medium flow, which we referred to as percolation, but due to coal mining, the influence of stress of rock mass will redistribute; it will inevitably affect the formation of the fissure zone of rock mass, which affects fluid seepage in rock mass; in the mining area, ecological restoration, protection, and restoration of aquifer are crucial. At present, scholars at home and abroad have studied more natural rock seepage, but less on the seepage characteristics under the influence of mining. In this paper, combining with the existing theory, 
TABLE 1: The face of 2301 of rock physical and mechanical properties.

\begin{tabular}{|c|c|c|c|c|c|c|c|}
\hline $\begin{array}{l}\text { Serial } \\
\text { number }\end{array}$ & Rock name & $\begin{array}{c}\text { Layer } \\
\text { thickness }(\mathrm{m})\end{array}$ & $\begin{array}{l}\text { Buried depth } \\
\text { (m) }\end{array}$ & $\begin{array}{l}\text { Bulk density } \\
\left(\mathrm{kg} / \mathrm{m}^{3}\right)\end{array}$ & $\begin{array}{l}\text { Compressive strength } \\
(\mathrm{MPa})\end{array}$ & $\begin{array}{l}\text { Tensile strength } \\
(\mathrm{MPa})\end{array}$ & $\begin{array}{l}\text { Elastic modulus } \\
(\mathrm{GPa})\end{array}$ \\
\hline 1 & $\begin{array}{l}\text { Weathered } \\
\text { mudstone }\end{array}$ & 43 & 43 & 2300 & 10.6 & 1.2 & 1.0 \\
\hline 2 & Sandstone & 104.2 & 147.2 & 2550 & 31.3 & 1.2 & 7.6 \\
\hline 3 & $\begin{array}{l}\text { Sand and } \\
\text { mudstone }\end{array}$ & 1.7 & 148.9 & 2730 & 66.7 & 1.8 & 6.2 \\
\hline 4 & 3 coal seams & 3.5 & 152.4 & 1420 & 27 & & 0.4 \\
\hline 5 & $\begin{array}{l}\text { Sandy } \\
\text { mudstone }\end{array}$ & 40.2 & 192.6 & 2610 & 35.3 & 2.8 & 1.2 \\
\hline
\end{tabular}

the computer numerical simulation method commonly used in the field of geotechnical science is used to analyze this kind of problem, which has very important significance [5-8].

\section{Brief Introduction of Previous Research Results}

The relation between the permeability coefficient $K_{h}$ and the stress $P$ obtained by Snow (1966) [9] is

$$
K_{h}=K_{0}+A\left[\frac{\rho g b^{2}}{4 \mu_{s}}\right] \frac{p-p_{0}}{K_{\mathrm{n}}},
$$

where $K_{0}$ is the initial stress; $P_{0}$ is the permeability coefficient of action; $K_{\mathrm{n}}$ is the normal stiffness of the crack; and $A$ is the coefficient.

Jones (1975) [9] proposed the empirical equation of permeability coefficient $K$ of rock fractures as follows:

$$
K=K_{0}\left[\log \frac{p_{h}}{p}\right]^{3},
$$

where $P_{h}$ is the effective stress of healing when $K=0$.

Louis et al. (1976) [9] obtained the following according to the borehole pumping test:

$$
\begin{aligned}
& K=K_{0} \exp (-\alpha \sigma), \\
& \sigma \approx \lambda H-p
\end{aligned}
$$

where $K_{0}$ is the surface permeability coefficient; $\gamma H$ is overburden weight; $P$ is water pressure; and $\alpha$ is the coefficient.

Kranz et al. (1979) [9] proposed the following formula to predict the change of permeability coefficient $(K)$ :

$$
K \propto-\left[\sigma_{c}-\frac{b}{a} p\right]
$$

In the formula, $b$ and $a$ are constant.

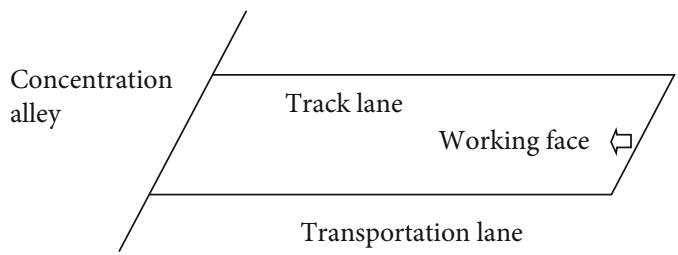

FIGURE 1: Roadway layout of working face.

Walsh (1981) [9] obtained the empirical formula of permeability coefficient and effective stress $\sigma_{e}$ as follows:

$$
K=K_{0}\left\{1-(\sqrt{2} \xi) \ln \left[\frac{\sigma_{e}}{\sigma_{e o}}\right]\right\}^{3},
$$

where $K_{0}$ is the initial permeability coefficient; $\sigma_{e o}$ is the initial effective stress, and $\xi$ is the coefficient related to the crack geometry size.

Kelsall (1984) [9] proposed a method to explain the influence of stress on the permeability coefficient of rock mass:

$$
K_{e}=K_{e o} \frac{\left[1+A\left[\sigma_{e o} / \xi\right]^{t}\right]^{3}}{\left[1+A\left[\sigma_{e} / \xi\right]^{t}\right]^{3}}
$$

where $K_{e}$ is the permeability coefficient when the effective stress is $\sigma_{\mathrm{e}}$ and $K_{e}$ acting on the $\sigma_{\mathrm{e}}$ main direction; and $A$, $T$, and $\xi$ are the material constants of rock mass fractures.

Bai and Elsworth (1989) [9] assumed that cracks were soft, and the following equation was determined:

$$
\Delta K=\frac{\rho g}{12 s^{\mu}}(b+s \Delta \varepsilon)^{3}
$$

where $\Delta \varepsilon$ is the strain perpendicular to the fracture group.

Zhang et al. [10] obtained the relationship between pressure, permeability coefficient, and seepage flow as follows:

$$
\begin{aligned}
& K=K_{0}\left[1+\frac{p-\gamma H\left(\cos ^{2} \theta+\lambda \sin ^{2} \theta\right)}{b K_{\mathrm{n}}}\right]^{4}, \\
& Q=Q_{0}\left[1+\frac{p-\gamma H\left(\cos ^{2} \theta+\lambda \sin ^{2} \theta\right)}{b K_{\mathrm{n}}}\right]^{4} .
\end{aligned}
$$




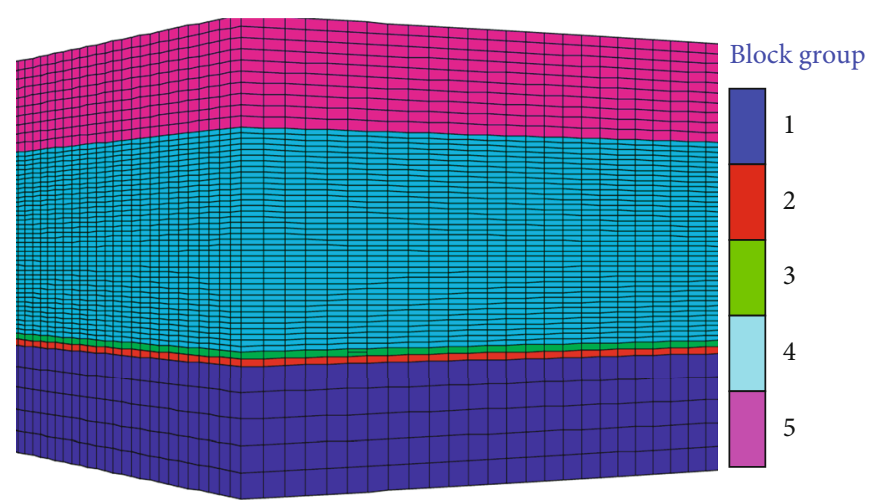

Figure 2: The establishment of the mechanical model. 1 sandy mudstone; 2 coal seams; 3 sand and mudstone; 4 sandstone; 5 weathered mudstone.

\section{Stress Seepage Coupling Numerical Simulation Analysis of Fractured Rock Mass}

3.1. Establishment of Mechanical Model. The 2301 working face of a mine is located in the desert area of Yulin area, the ecological environment is fragile, the working face is located in the 3 coal seam, the average thickness is 3.5 meters, and the overburden contains aquifer, which has an important impact on the mining of coal mine; improper mining will cause the accident of water inrush and sand. According to the rock mechanics experiment, the rock mechanics parameters are obtained (Table 1).

According to the roadway layout characteristics of 2301 working face and the near-horizontal coal seam (as shown in Figure 1), in order to improve the calculation efficiency, the design model is shown in Figure 2. This simulation is mainly to analyze the distribution law and development height of caving zone and fracture zone with overlying aquifers. The entire overlying rock and a small part of the floor should be considered when designing the model, which is to analyze the coordination of coal seam, roof, and floor; this is key to analyze the problem. This thesis has certain pore water pressure of the aquifer as module, located $10 \mathrm{~m}$ beneath the floor of the overlying strata in the process of working face advancing; fluid-structure interaction phenomenon has mutual influence, the change of pore water pressure in the rock mass causes stress variation in the mining, and water may exist in the crack, and the crack volume changes; it will have an effect on pore water pressure; this model uses the fluid calculation and mechanical calculation; at the same time, it also is often said that the fluid-structure coupling calculation adopts the model of seepage flow in the calculation and isotropic seepage model, calculating result in order to achieve. In the model, the range of coal seam roof above is until $148.9 \mathrm{~m}$ as a model of the upper surface and a layer of rock as a model of the base plate; each side of the model scales out $50 \mathrm{~m}$; boundary treatment is the key problem of the model; the specific process is as follows: on the left and right boundary of the model, take $u=0$, $v=0$ ( $u$ for the $X$ axis displacement, $v$ for the $Y$ direction displacement, namely, single constraint boundary). At the bottom boundary of the model, $u=v=0$ is the fully constrained boundary. The upper boundary of the model is the ground surface [11-15], which is regarded as free boundary without constraint [16-18].

3.2. Coupling Analysis of Stress and Seepage. The movement of the overlying strata in coal mining leads to the redistribution of stress, which is bound to affect the flow of fluid in the fracture, and the key parameter is the permeability coefficient, which reflects the flow law of fluid and also reflects the development law of fracture in the overlying strata.

3.2.1. Horizontal Movement Law of Overburden. Due to the influence of working face mining, each unit of the mathematical model has to undergo continuous deformation. In order to clearly display the horizontal displacement change process of each node unit, the displacement calculation results of each node were output along with the working face advancing, and the displacement cloud maps of 2301 working face with different lengths and different stoping stages were drawn. The horizontal displacement cloud maps of working face advancing with $100 \mathrm{~m}$, $150 \mathrm{~m}, 200 \mathrm{~m}$, and $250 \mathrm{~m}$ are shown in Figures 3-5 respectively.

In the working face, the phase of initial overall overburden deformation is not large, including horizontal deformation value; this is due to the fact that the immediate roof is not fully caving; the supporting role, on both sides of the mined-out area, has the opposite change; there is displacement of the change in the opposite direction; its value is nearer the mined-out area; the greater the distance of the far mined-out area, the more and more small, along with the mining, mine pressure release, the overburden, and the horizontal displacement of zero, sometimes at the same time, due to the restriction of the boundary conditions, the model, and the lower part of the border around the border; the strata horizontal displacement value is separated into four areas: there are negative 


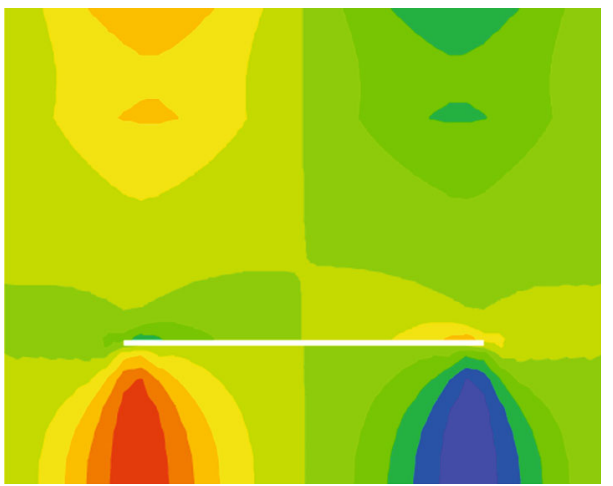

Contour of $X$-displacement

Plane: on

Magfac $=0.000 e+000$

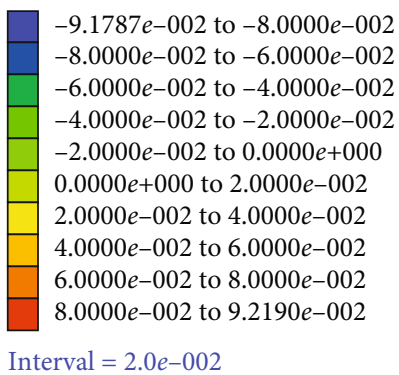

(a) $100 \mathrm{~m}$ horizontal displacement cloud map

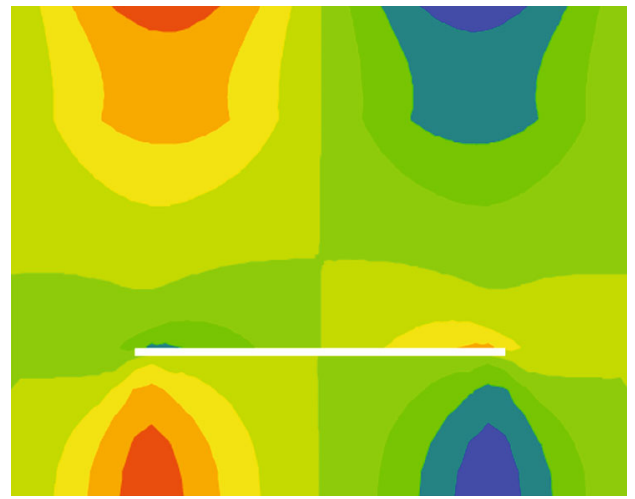

Contour of $X$-displacement

Plane: on

Magfac $=0.000 e+000$

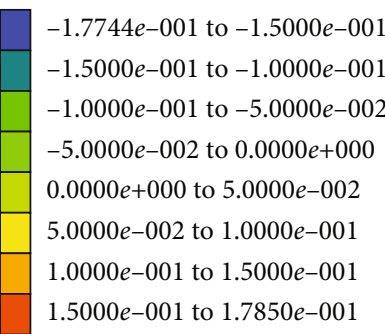

(b) $150 \mathrm{~m}$ horizontal displacement cloud map

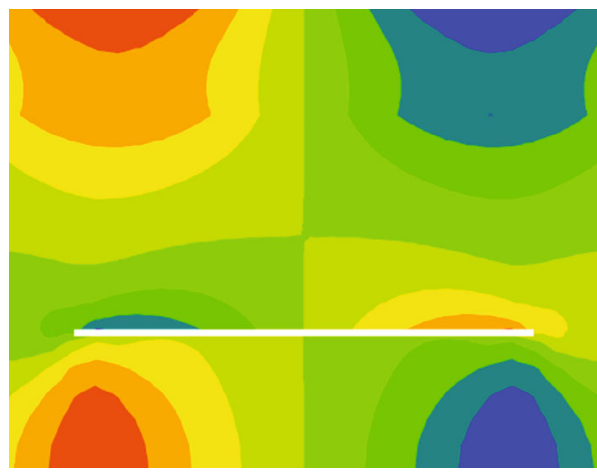

Contour of $X$-displacement

Plane: on

Magfac $=0.000 e+000$

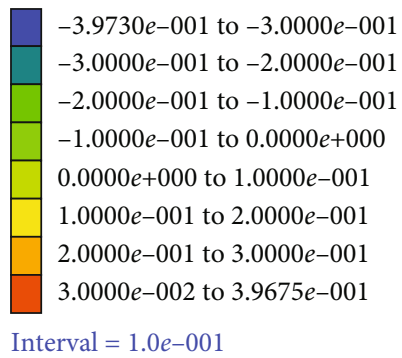

(c) $200 \mathrm{~m}$ horizontal displacement cloud map

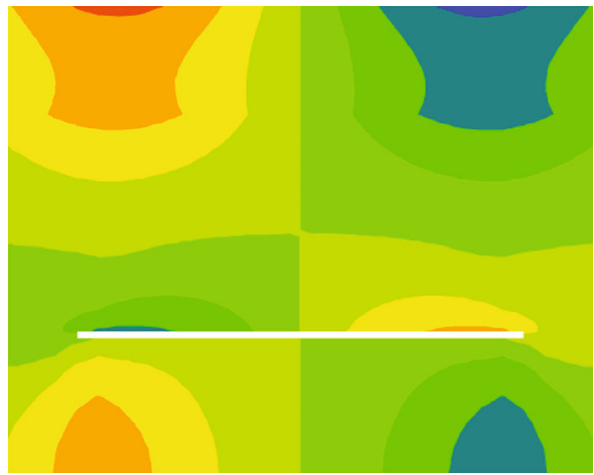

Contour of $X$-displacement

Plane: on

Magfac $=0.000 e+000$

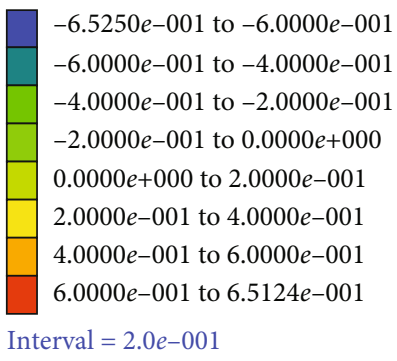

(d) $250 \mathrm{~m}$ horizontal displacement cloud map

Figure 3: Horizontal displacement cloud map of different stoping stages $(100 \mathrm{~m}, 150 \mathrm{~m}, 200 \mathrm{~m}$, and $250 \mathrm{~m})$ when the length of working face is $200 \mathrm{~m}$. 


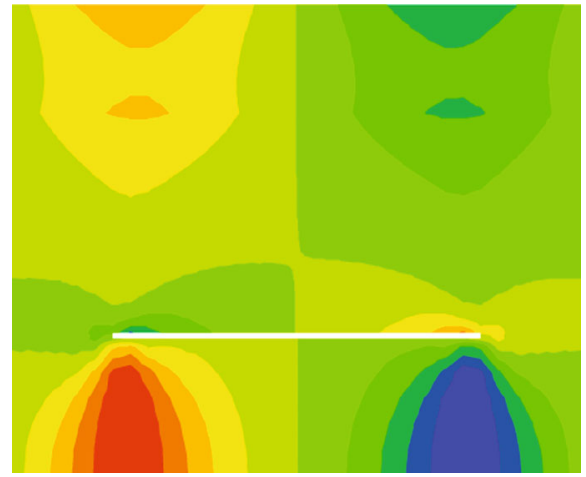

Contour of $X$-displacement

Plane: on

Magfac $=0.000 e+000$

$-9.8722 e-002$ to $-8.0000 e-002$

$-8.0000 e-002$ to $-6.0000 e-002$

$-6.0000 e-002$ to $-4.0000 e-002$

$-4.0000 e-002$ to $-2.0000 e-002$

$-2.0000 e-002$ to $0.0000 e+000$

$0.0000 e+000$ to $2.0000 e-002$

$2.0000 e-002$ to $4.0000 e-002$

$4.0000 e-002$ to $6.0000 e-002$

$6.0000 e-002$ to $8.0000 e-002$

$8.0000 e-002$ to $9.9099 e-002$

(a) $100 \mathrm{~m}$ horizontal displacement cloud map

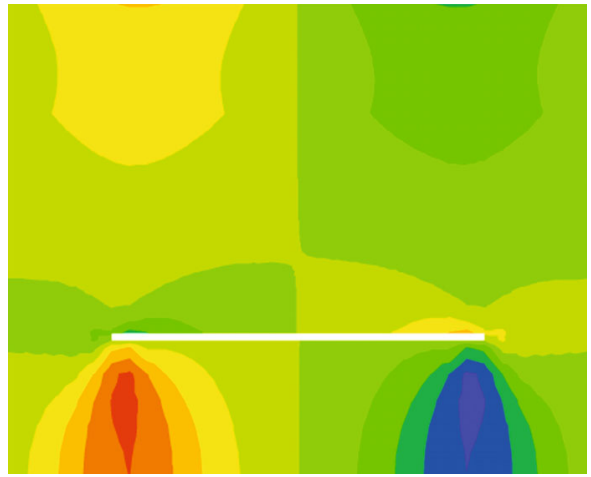

Contour of $X$-displacement

Plane: on

Magfac $=0.000 e+000$

$-1.0712 e-001$ to $-1.0000 e-001$

$-1.0000 e-001$ to $-7.5000 e-002$

$-7.5000 e-002$ to $-5.0000 e-002$

$-5.0000 e-002$ to $-2.5000 e-002$

$-2.5000 e-002$ to $0.0000 e+000$

$0.0000 e+000$ to $2.5000 e-002$

$2.5000 e-002$ to $5.0000 e-002$

$5.0000 e-002$ to $7.5000 e-002$

$7.5000 e-002$ to $1.0000 e-001$

$1.0000 e-001$ to $1.0748 e-001$

(b) $150 \mathrm{~m}$ horizontal displacement cloud map

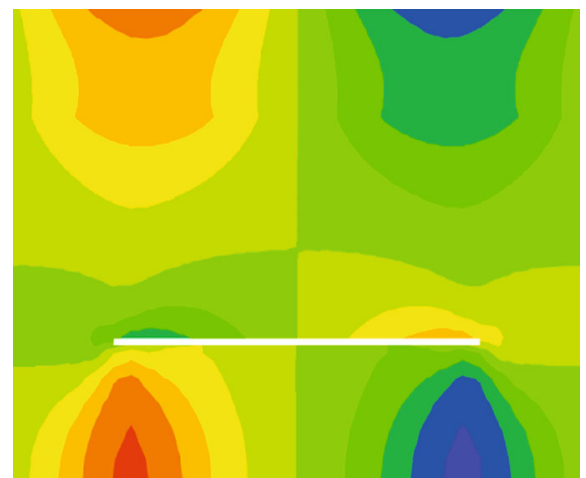
Contour of $X$-displacement
Plane: on
Magfac $=0.000 e+000$
$\square-2.1058 e-001$ to $-2.0000 e-001$
$-2.0000 e-001$ to $-1.5000 e-001$
$-1.5000 e-001$ to $-1.0000 e-001$
$-1.0000 e-001$ to $-5.0000 e-002$
$-5.0000 e-002$ to $0.0000 e+000$
$0.0000 e+000$ to $5.0000 e-002$
$5.0000 e-002$ to $1.0000 e-001$
$1.0000 e-001$ to $1.5000 e-001$
$1.5000 e-001$ to $2.0000 e-001$
$2.0000 e-001$ to $2.0939 e-001$

(c) $200 \mathrm{~m}$ horizontal displacement cloud map

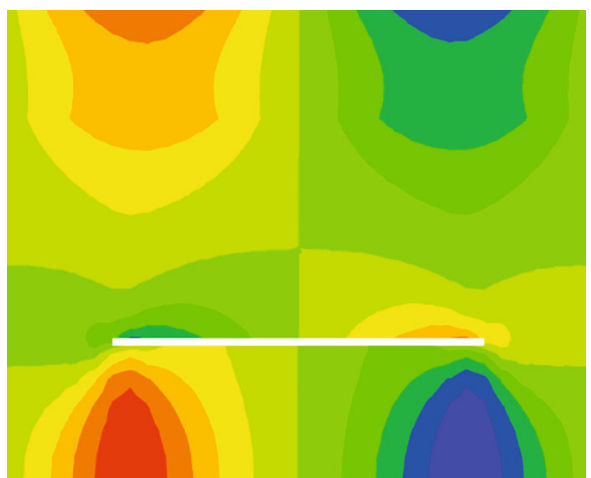

Contour of $X$-displacement

Plane: on

Magfac $=0.000 e+000$

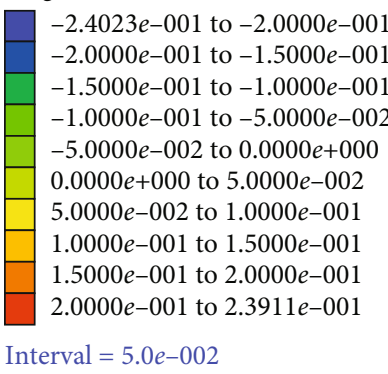

(d) $250 \mathrm{~m}$ horizontal displacement cloud map

FIGURE 4: Horizontal displacement cloud map of different stoping stages $(100 \mathrm{~m}, 150 \mathrm{~m}, 200 \mathrm{~m}$, and $250 \mathrm{~m})$ when the working face length is $220 \mathrm{~m}$. 


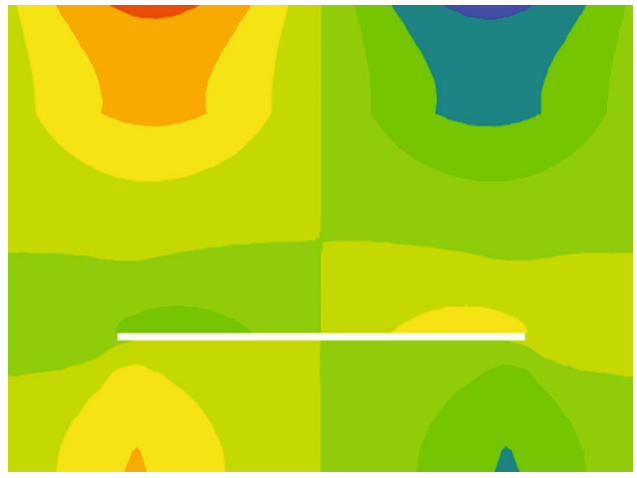

Contour of $X$-displacement

Plane: on

Magfac $=0.000 e+000$

$\square$

$-3.3317 e-001$ to $-3.0000 e-001$

$-3.0000 e-001$ to $-2.0000 e-001$

$-2.0000 e-001$ to $-1.0000 e-001$

$-1.0000 e-001$ to $0.0000 e+000$

$0.0000 e+000$ to $1.0000 e-001$

$1.0000 e-001$ to $2.0000 e-001$

$2.0000 e-001$ to $3.0000 e-001$

$3.0000 e-001$ to $3.3242 e-001$

(a) $100 \mathrm{~m}$ horizontal displacement cloud map

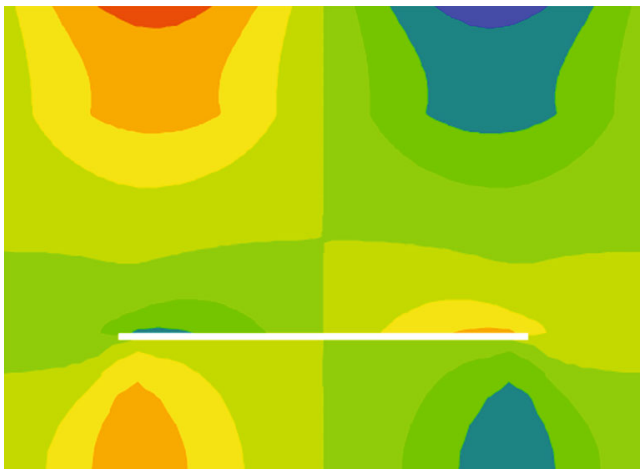

Contour of $X$-displacement

Plane: on

Magfac $=0.000 e+000$

$-3.5207 e-001$ to $-3.0000 e-001$

$-3.0000 e-001$ to $-2.0000 e-001$

$-2.0000 e-001$ to $-1.0000 e-001$

$-1.0000 e-001$ to $0.0000 e+000$

$0.0000 e+000$ to $1.0000 e-001$

$1.0000 e-001$ to $2.0000 e-001$

$2.0000 e-001$ to $3.0000 e-001$

$3.0000 e-001$ to $3.5161 e-001$

(b) $150 \mathrm{~m}$ horizontal displacement cloud map

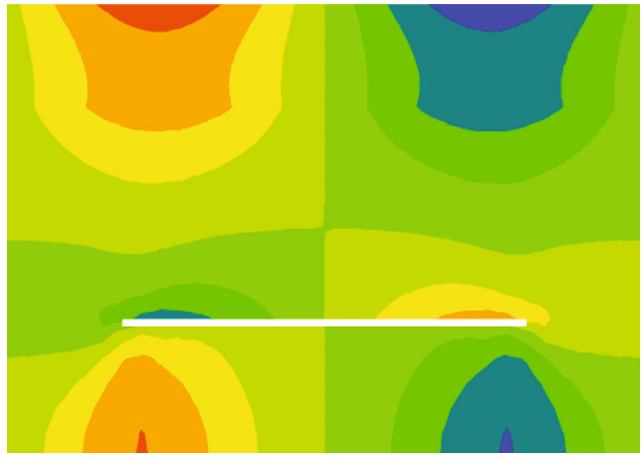

Contour of $X$-displacement

Plane: on

Magfac $=0.000 e+000$

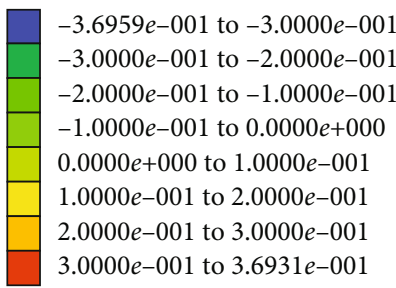

(c) $200 \mathrm{~m}$ horizontal displacement cloud map

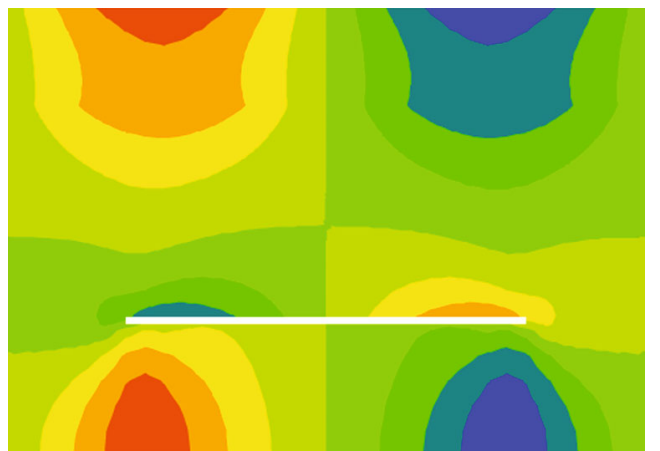

Contour of $X$-displacement

Plane: on

Magfac $=0.000 e+000$

$-3.9730 e-001$ to $-3.0000 e-001$

$-3.0000 e-001$ to $-2.0000 e-001$

$-2.0000 e-001$ to $-1.0000 e-001$

$-1.0000 e-001$ to $0.0000 e+000$

$0.0000 e+000$ to $1.0000 e-001$

$1.0000 e-001$ to $2.0000 e-001$

$2.0000 e-001$ to $3.0000 e-001$

$3.0000 e-001$ to $3.9675 e-001$

(d) $250 \mathrm{~m}$ horizontal displacement cloud map

Figure 5: Horizontal displacement cloud map of different stoping stages $(100 \mathrm{~m}, 150 \mathrm{~m}, 200 \mathrm{~m}$, and $250 \mathrm{~m})$ when the working face length is $240 \mathrm{~m}$.

moving area, positive moving area far away from the goaf, and positive moving area and negative moving area near the goaf.
3.2.2. Vertical Movement Law of Overburden. In the different stages of 2301 working face, the vertical subsidence curve shape of overlying rocks does not change much in the process 


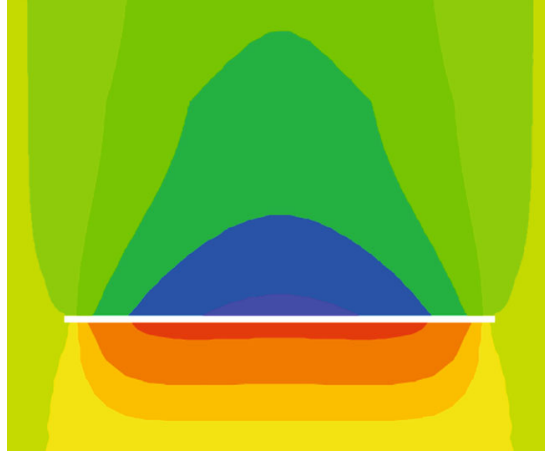

Contour of Z-displacement

Plane: on

Magfac $=0.000 e+000$

$-1.0641 e+000$ to $-1.0000 e+000$

$-1.0000 e+000$ to $-8.0000 e-001$

$-8.0000 e-001$ to $-6.0000 e-001$

$-6.0000 e-001$ to $-4.0000 e-001$

$-4.0000 e-001$ to $-2.0000 e-001$

$-2.0000 e-001$ to $0.0000 e+000$

$0.0000 e+000$ to $2.0000 e-001$

$2.0000 e-001$ to $4.0000 e-001$

$4.0000 e-001$ to $6.0000 e-001$

$6.0000 e-001$ to $6.4715 e-001$

(a) $100 \mathrm{~m}$ vertical displacement cloud map

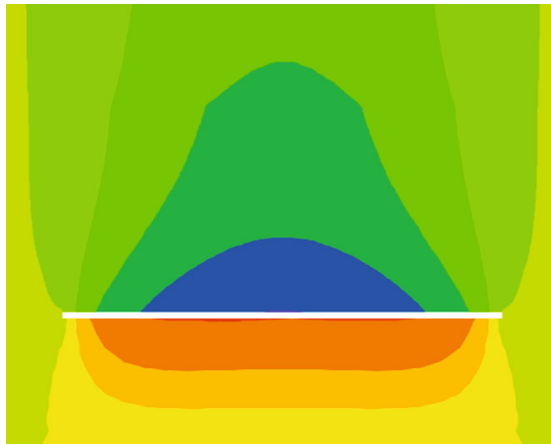

Contour of Z-displacement

Plane: on

Magfac $=0.000 e+000$

$-1.0041 e+000$ to $-1.0000 e+000$

$-1.0000 e+000$ to $-8.0000 e-001$

$-8.0000 e-001$ to $-6.0000 e-001$

$-6.0000 e-001$ to $-4.0000 e-001$

$-4.0000 e-001$ to $-2.0000 e-001$

$-2.0000 e-001$ to $0.0000 e+000$

$0.0000 e+000$ to $2.0000 e-001$

$2.0000 e-001$ to $4.0000 e-001$

$4.0000 e-001$ to $6.0000 e-001$

$6.0000 e-001$ to $6.0795 e-001$

(b) $150 \mathrm{~m}$ vertical displacement cloud map

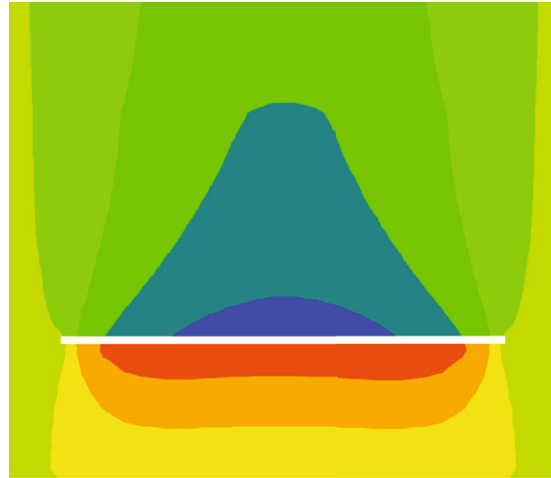

Contour of $Z$-displacement

Plane: on

Magfac $=0.000 e+000$

-9.0585e-001 to $-8.0000 e-001$

$-8.0000 e-001$ to $-6.0000 e-001$

$-6.0000 e-001$ to $-4.0000 e-001$

$-4.0000 e-001$ to $-2.0000 e-001$

$-2.0000 e-001$ to $0.0000 e+000$

$0.0000 e+000$ to $2.0000 e-001$

$2.0000 e-001$ to $4.0000 e-001$

$4.0000 e-001$ to $5.0626 e-001$

Interval $=2.0 e-001$

(c) $200 \mathrm{~m}$ vertical displacement cloud map

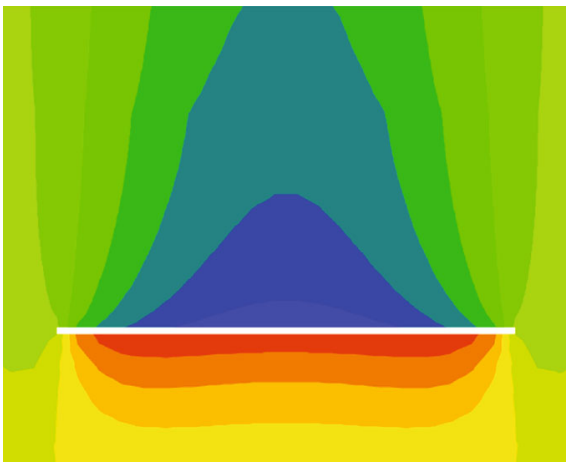

Contour of $Z$-displacement

Plane: on

Magfac $=0.000 e+000$

$-7.8915 e-001$ to $-7.0000 e-001$

$-7.0000 e-001$ to $-6.0000 e-001$

$-6.0000 e-001$ to $-5.0000 e-001$

$-5.0000 e-001$ to $-4.0000 e-001$

$-4.0000 e-001$ to $-3.0000 e-001$

$-3.0000 e-001$ to $-2.0000 e-001$

$-2.0000 e-001$ to $-1.0000 e-001$

$-1.0000 e-001$ to $0.0000 e+000$

$0.0000 e+000$ to $1.0000 e-001$

$0.0000 e+000$ to $1.0000 e-001$
$1.0000 e-001$ to $2.0000 e-001$

$2.0000 e-001$ to $3.0000 e-001$

$3.0000 e-001$ to $3.8555 e-001$

(d) $250 \mathrm{~m}$ vertical displacement cloud map

Figure 6: Vertical displacement cloud map of different stoping stages $(100 \mathrm{~m}, 150 \mathrm{~m}, 200 \mathrm{~m}$, and $250 \mathrm{~m})$ when the length of working face is $200 \mathrm{~m}$.

of working face advancement, and the changes of each rock layer are basically the same; whether it is hard rock or soft rock, all are coordinated deformation.
In the overburden on the vertical displacement of the funnel characteristics, in early mining, the vertical displacement is not big, but the amount of propulsion, strata of 


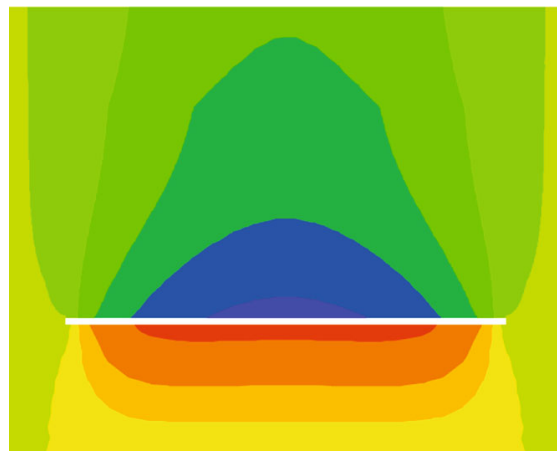

Contour of Z-displacement

Plane: on

Magfac $=0.000 e+000$

$\square-1.0641 e-000$ to $-1.0000 e+000$

$-1.0000 e+000$ to $-8.0000 e-001$

$-8.0000 e-001$ to $-6.0000 e-001$

$-6.0000 e-001$ to $-4.0000 e-001$

$-4.0000 e-001$ to $-2.0000 e-001$

$-2.0000 e-001$ to $0.0000 e+000$

$0.0000 e+000$ to $2.0000 e-001$

$2.0000 e-001$ to $4.0000 e-001$

$4.0000 e-001$ to $6.0000 e-001$

$6.0000 e-001$ to $6.4715 e-001$

(a) $100 \mathrm{~m}$ vertical displacement cloud map

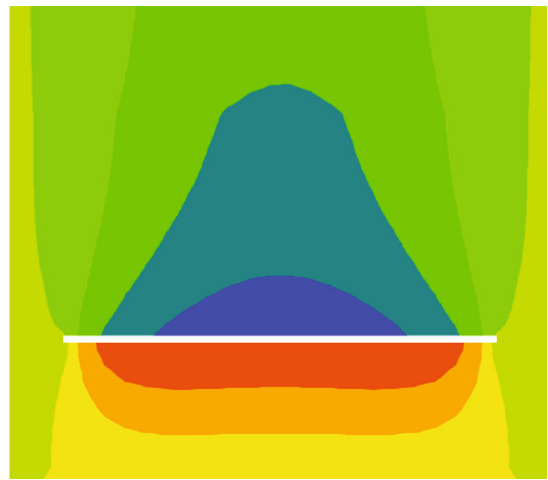

Contour of Z-displacement

Plane: on

Magfac $=0.000 e+000$

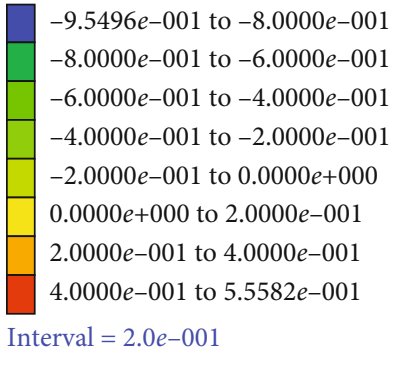

(b) $150 \mathrm{~m}$ vertical displacement cloud map

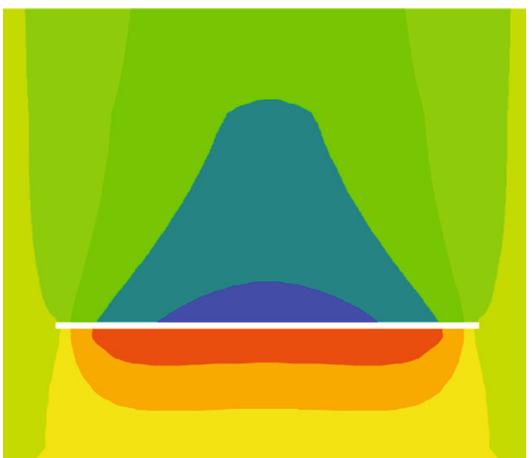

Contour of $Z$-displacement

Plane: on

Magfac $=0.000 e+000$

] $-9.1567 e-001$ to $-8.0000 e-001$

$-8.0000 e-001$ to $-6.0000 e-001$

$-6.0000 e-001$ to $-4.0000 e-001$

$-4.0000 e-001$ to $-2.0000 e-001$

$-2.0000 e-001$ to $0.0000 e+000$

$0.0000 e+000$ to $2.0000 e-001$

$2.0000 e-001$ to $4.0000 e-001$

$4.0000 e-001$ to $5.1618 e-001$

(c) $200 \mathrm{~m}$ vertical displacement cloud map

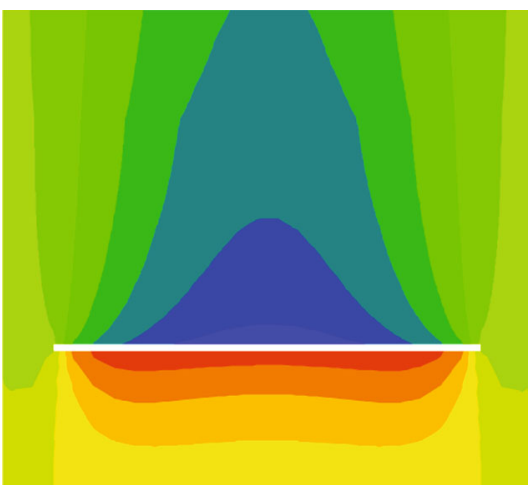

Contour of Z-displacement

Plane: on

Magfac $=0.000 e+000$

$-7.7456 e-001$ to $-7.0000 e-00$

$-7.0000 e-001$ to $-6.0000 e-001$

$-6.0000 e-001$ to $-5.0000 e-001$

$-5.0000 e-001$ to $-4.0000 e-001$

$-4.0000 e-001$ to $-3.0000 e-001$

$-3.0000 e-001$ to $-2.0000 e-001$

$-2.0000 e-001$ to $-1.0000 e-001$

$-1.0000 e-001$ to $0.0000 e+000$

$0.0000 e+000$ to $1.0000 e-001$

$1.0000 e-001$ to $2.0000 e-001$

$2.0000 e-001$ to $3.0000 e-001$

$3.0000 e-001$ to $3.7046 e-001$

(d) $250 \mathrm{~m}$ vertical displacement cloud map

Figure 7: Vertical displacement cloud map of different stoping stages (100 m, $150 \mathrm{~m}, 200 \mathrm{~m}$, and $250 \mathrm{~m})$ when working face length is $220 \mathrm{~m}$.

vertical displacement, and the maximum value appeared in the middle of the mined-out area. This is because in the middle of the mined-out area, without support, the rock strata have a greater range of movement, and from the picture that looks like a funnel, when mining fully, strata are not a big change, its change of displacement distribution is 


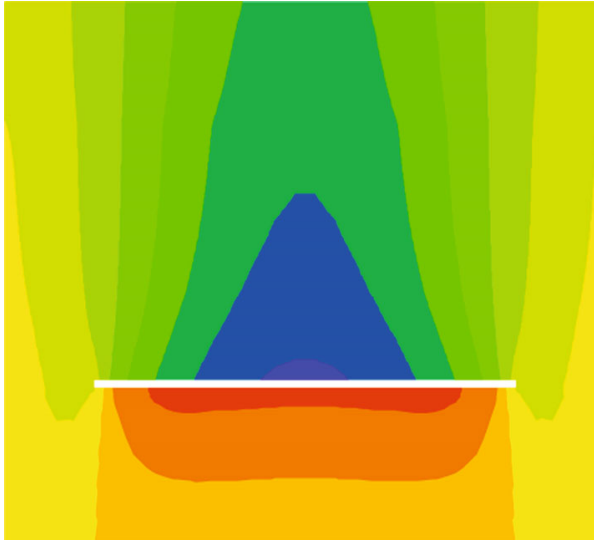

Contour of Z-displacement Plane: on

Magfac $=0.000 e+000$

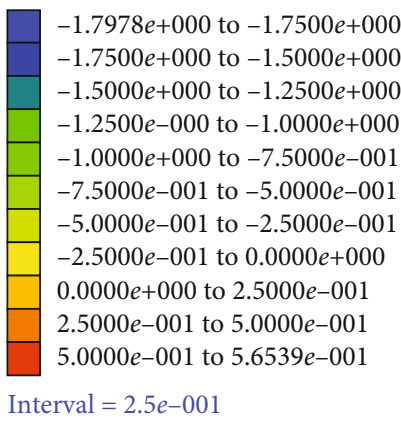

(a) $100 \mathrm{~m}$ vertical displacement cloud map

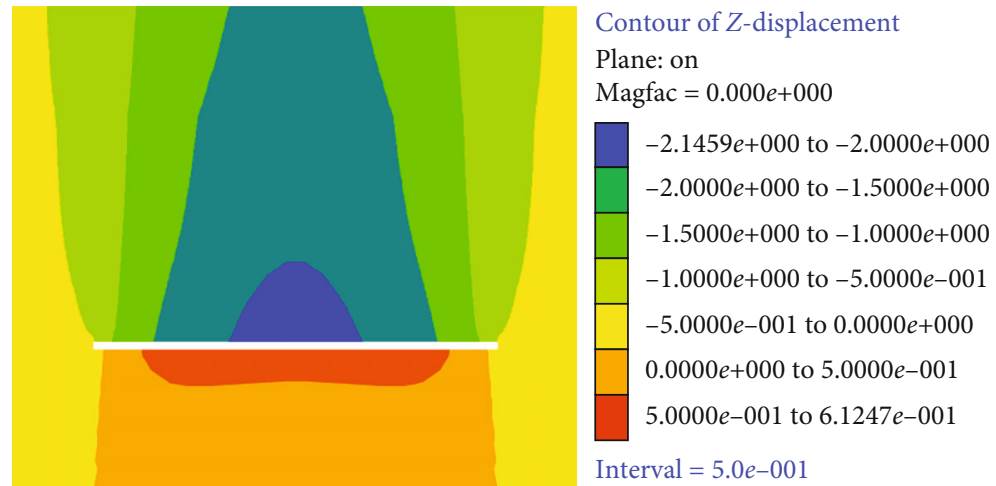

(b) $150 \mathrm{~m}$ vertical displacement cloud map

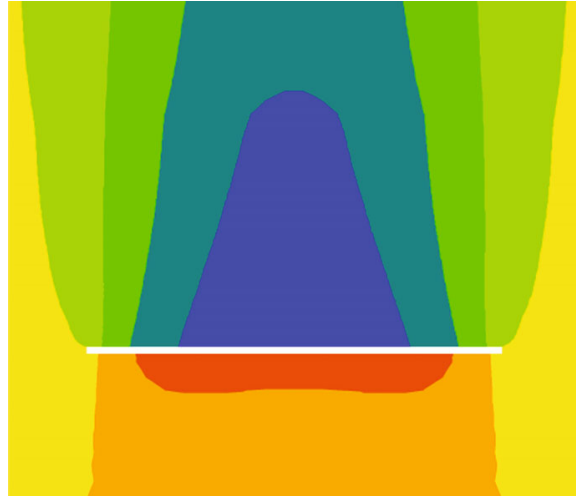

Contour of Z-displacement

Plane: on

Magfac $=0.000 e+000$

$\square-2.4956 e+000$ to $-2.0000 e+000$

$-2.0000 e+000$ to $-1.0000 e+000$

$-1.5000 e+000$ to $-1.0000 e+000$

$-1.0000 e+000$ to $-5.0000 e-001$

$-5.0000 e-001$ to $0.0000 e+000$

$0.0000 e+000$ to $5.0000 e-001$

$5.0000 e-001$ to $6.3406 e-001$

(c) $200 \mathrm{~m}$ vertical displacement cloud map

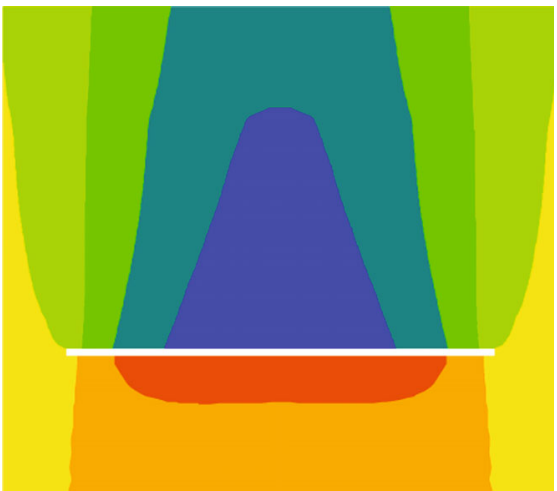

Contour of $Z$-displacement

Plane: on

Magfac $=0.000 e+000$

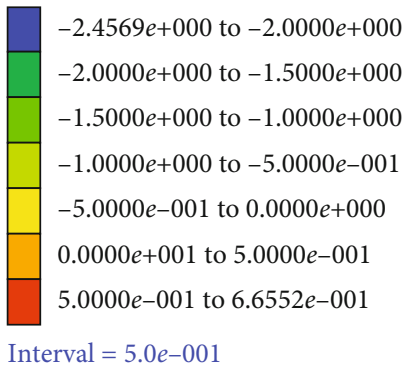

(d) $250 \mathrm{~m}$ vertical displacement cloud map

Figure 8: Vertical displacement cloud map of different stoping stages $(100 \mathrm{~m}, 150 \mathrm{~m}, 200 \mathrm{~m}$, and $250 \mathrm{~m})$ when working face length is $240 \mathrm{~m}$. 


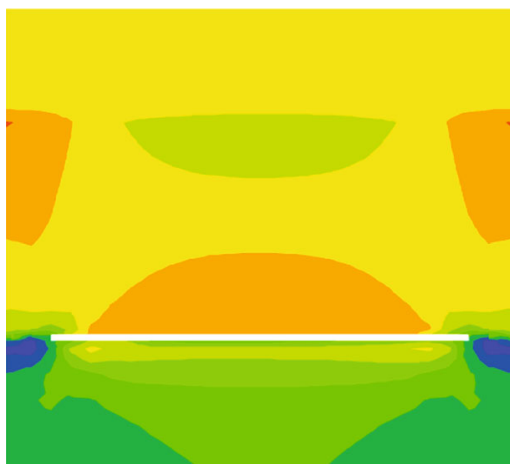

Contour of SXX

Plane: on

Magfac $=0.000 e+000$

Gradient calculation

$-1.5076 e+007$ to $-1.4000 e+007$ $-1.4000 e+007$ to $-1.2000 e+007$ $-1.2000 e+007$ to $-1.0000 e+007$

$-1.0000 e+007$ to $-8.0000 e+006$ $-8.0000 e+006$ to $-6.0000 e+006$ $-6.0000 e+006$ to $-4.0000 e+006$ $-4.0000 e+006$ to $-2.0000 e+006$ $-2.0000 e+006$ to $0.0000 e+000$ $0.0000 e+000$ to $4.4005 e+005$ Interval $=2.0 e+006$

(a) $100 \mathrm{~m}$ horizontal stress nephogram

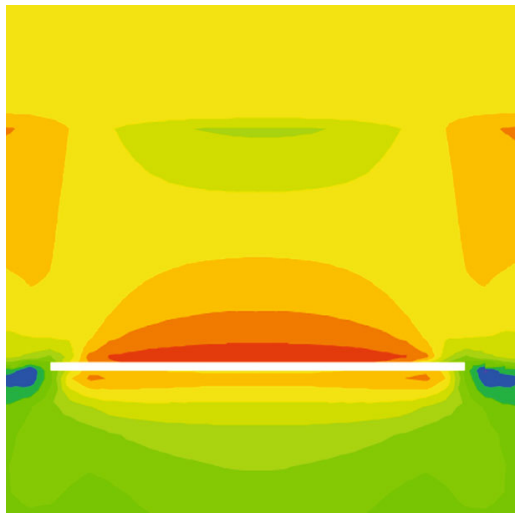

Contour of SXX

Plane: on

Magfac $=0.000 e+000$

Gradient calculation

$\square-1.6412 e+007$ to $-1.6000 e+007$

$-1.6000 e+007$ to $-1.4000 e+007$

$-1.4000 e+007$ to $-1.2000 e+007$

$-1.2000 e+007$ to $-1.0000 e+007$

$-1.0000 e+007$ to $-8.0000 e+006$

$-8.0000 e+006$ to $-6.0000 e+006$

$-6.0000 e+006$ to $-4.0000 e+006$

$-4.0000 e+006$ to $-2.0000 e+006$

$-2.0000 e+006$ to $0.4005 e+000$

$0.0000 e+000$ to $2.0000 e+006$

$2.0000 e+006$ to $3.1653 e+006$

(b) $150 \mathrm{~m}$ horizontal stress nephogram

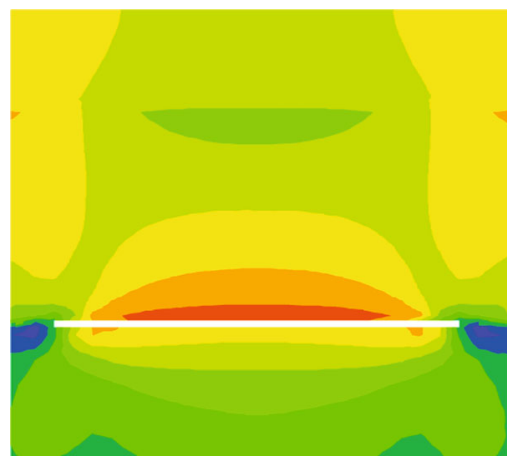
Contour of SXX
Plane: on
Magfac $=0.000 e+000$
Gradient calculation
$-1.6620 e+007$ to $-1.5000 e+007$
$-1.5000 e+007$ to $-1.2500 e+007$
$-1.2500 e+007$ to $-1.0000 e+007$
$-1.0000 e+007$ to $-7.5000 e+006$
$-7.5000 e+006$ to $-5.0000 e+006$
$-5.0000 e+006$ to $-2.5000 e+006$
$-2.5000 e+006$ to $0.0000 e+000$
$0.0000 e+000$ to $2.5000 e+006$
$2.5000 e+006$ to $3.3992 e+006$
Interval $=2.5 e+006$

(c) $200 \mathrm{~m}$ horizontal stress nephogram

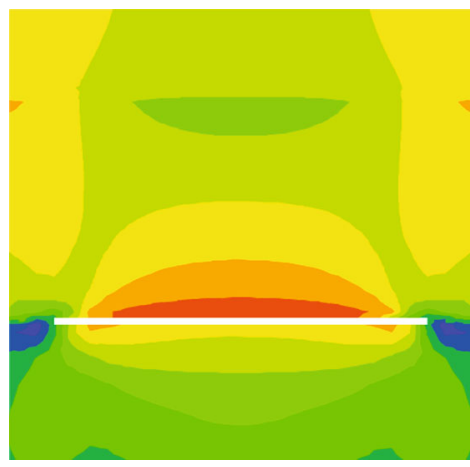

Contour of SXX

Plane: on

Magfac $=0.000 e+000$

Gradient calculation

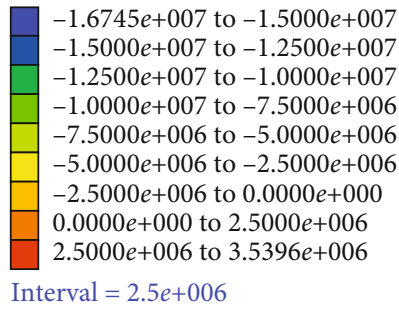

(d) $250 \mathrm{~m}$ horizontal stress nephogram

FIGURE 9: Horizontal stress nephogram of different stoping stages $(100 \mathrm{~m}, 150 \mathrm{~m}, 200 \mathrm{~m}$, and $250 \mathrm{~m})$ when the length of working face is $200 \mathrm{~m}$. 


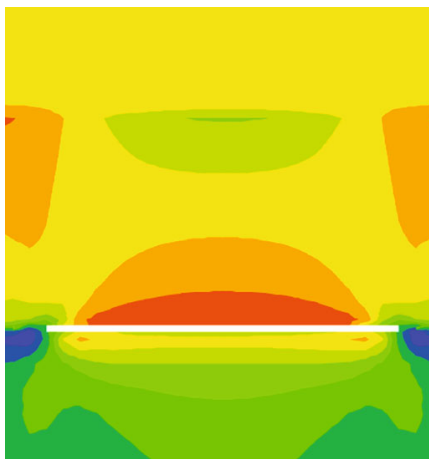

Contour of SXX

Plane: on

Magfac $=0.000 e+000$

Gradient calculation

(a) $100 \mathrm{~m}$ horizontal stress nephogram
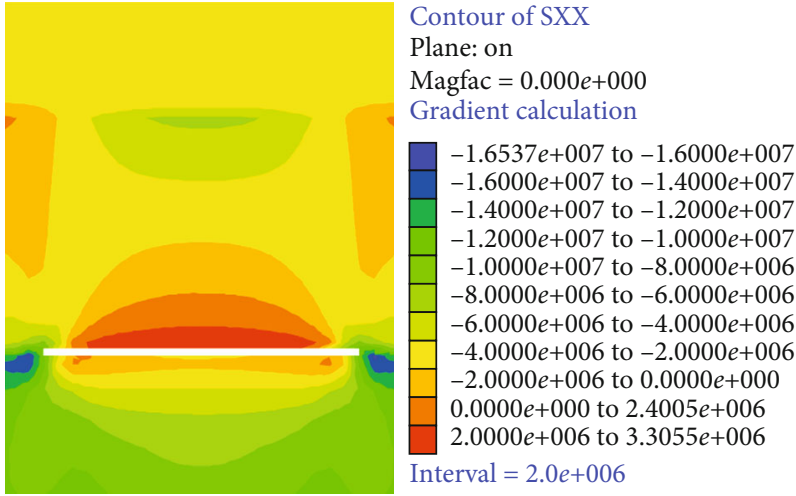

(b) $150 \mathrm{~m}$ horizontal stress nephogram

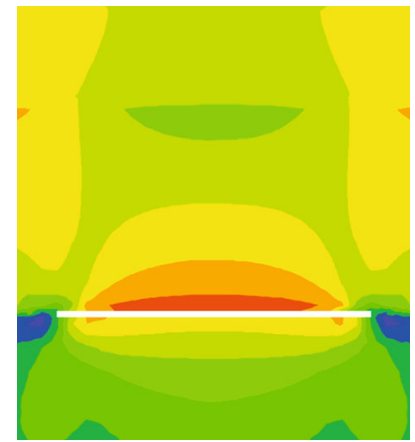

Contour of SXX

Plane: on

Magfac $=0.000 e+000$

Gradient calculation

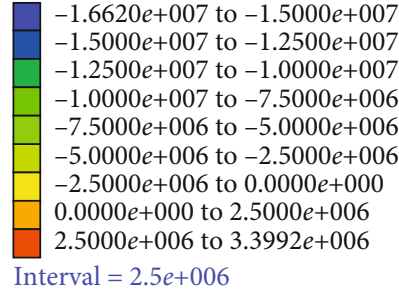

(c) $200 \mathrm{~m}$ horizontal stress nephogram

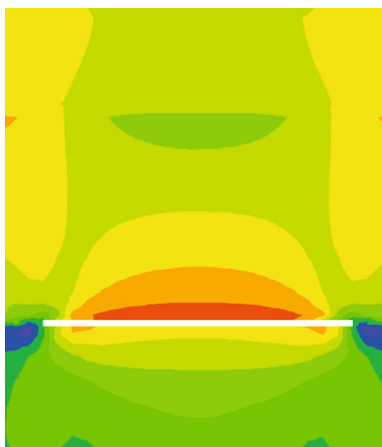

$$
\begin{aligned}
& \text { Contour of SXX } \\
& \text { Plane: on } \\
& \text { Magfac }=0.000 e+000 \\
& \text { Gradient calculation } \\
& -1.6703 e+007 \text { to }-1.5000 e+007 \\
& -1.5000 e+007 \text { to }-1.2500 e+007 \\
& -1.2500 e+007 \text { to }-1.0000 e+007 \\
& -1.0000 e+007 \text { to }-7.5000 e+006 \\
& -7.5000 e+006 \text { to }-5.0000 e+006 \\
& -5.0000 e+006 \text { to }-2.5000 e+006 \\
& -2.5000 e+006 \text { to } 0.0000 e+000 \\
& 0.0000 e+000 \text { to } 2.5000 e+006 \\
& 2.5000 e+006 \text { to } 3.4928 e+006 \\
& \text { Interval }=2.5 e+006
\end{aligned}
$$

(d) $250 \mathrm{~m}$ horizontal stress nephogram

Figure 10: Horizontal stress nephogram of different stoping stages ( $100 \mathrm{~m}, 150 \mathrm{~m}, 200 \mathrm{~m}$, and $250 \mathrm{~m})$ when the working face length is $220 \mathrm{~m}$.

symmetrical, goaf in the working face advances continuously in the process of filling, and vertical displacement of overburden rock will then move forward, until it is focused on the coal wall.
From the vertical displacement cloud maps of different mining stages, in the beginning stage, the displacement cloud maps in the vertical direction are not very large either in size or in advance influence range. With the 


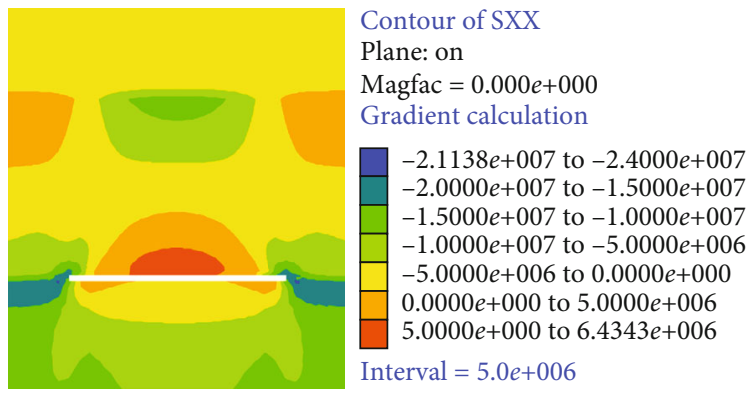

(a) $100 \mathrm{~m}$ horizontal stress nephogram

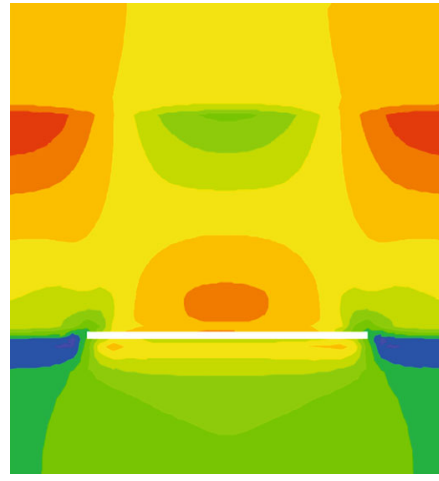
Contour of SXX
Plane: on
Magfac $=0.000 e+000$
Gradient calculation
$-1.8555 e+007$ to $-1.75000 e+007$
$-1.75000 e+007$ to $-1.5000 e+007$
$-1.5000 e+007$ to $-1.2500 e+007$
$-1.2500 e+007$ to $-1.0000 e+006$
$-1.0000 e+006$ to $-7.5000 e+006$
$-7.5000 e+006$ to $-5.0000 e+006$
$-5.0000 e+006$ to $-2.5000 e+006$
$-2.5000 e+006$ to $0.0000 e+000$
$0.0000 e+006$ to $2.5000 e+006$
$2.5000 e+000$ to $4.5751 e+006$
Interval $=2.5 e+006$

(b) $150 \mathrm{~m}$ horizon al stress nephogram

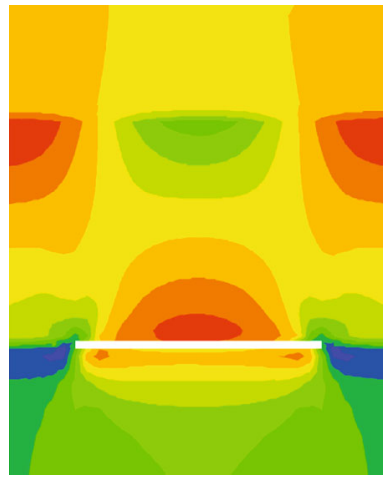

$$
\begin{aligned}
& \text { Contour of SXX } \\
& \text { Plane: on } \\
& \text { Magfac }=0.000 e+000 \\
& \text { Gradient calculation } \\
& \begin{array}{|}
-1.9591 e+007 \text { to }-1.7500 e+007 \\
-1.7500 e+007 \text { to }-1.5000 e+007 \\
-1.5000 e+007 \text { to }-1.2500 e+007 \\
-1.2500 e+007 \text { to }-1.0000 e+007 \\
-1.0000 e+007 \text { to }-7.5000 e+006 \\
-7.5000 e+006 \text { to }-5.0000 e+006 \\
-5.0000 e+006 \text { to }-2.5000 e+006 \\
-2.5000 e+006 \text { to } 0.0000 e+000 \\
0.0000 e+000 \text { to } 2.5000 e+006 \\
2.5000 e+006 \text { to } 4.5765 e+006
\end{array} \\
& \text { Interval }=2.5 e+006
\end{aligned}
$$

(c) $200 \mathrm{~m}$ horizontal stress nephogram
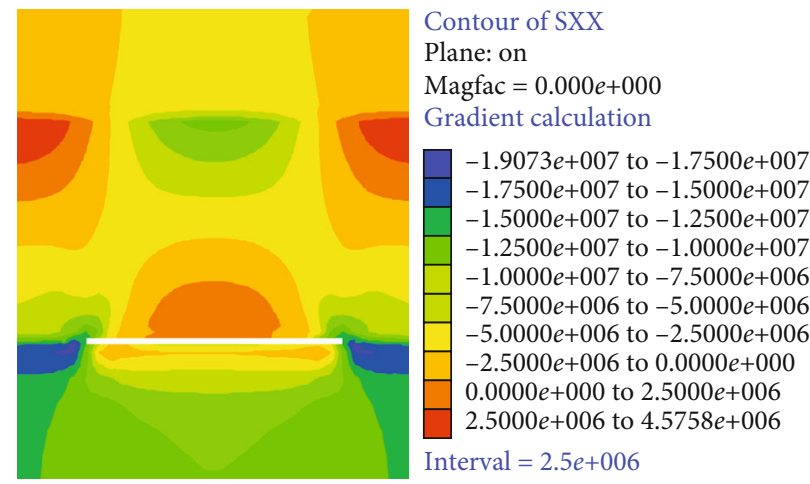

(d) $250 \mathrm{~m}$ horizontal stress nephogram

Figure 11: Horizontal stress nephogram of different stoping stages $(100 \mathrm{~m}, 150 \mathrm{~m}, 200 \mathrm{~m}$, and $250 \mathrm{~m})$ when the working face length is $240 \mathrm{~m}$.

increase of distance, these changes also increase, and the vertical displacement cloud map gradually becomes unclosed (Figures 6-8).
3.2.3. Horizontal Stress Distribution in Rock Mass. Numerical simulation results show that the early mining overburden horizontal stress is not big. However, the zoning of the 

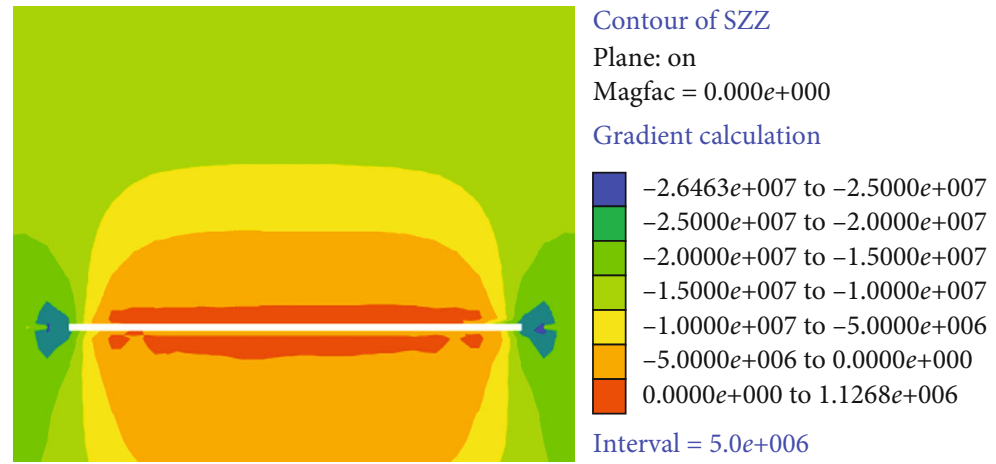

(a) $100 \mathrm{~m}$ vertical stress nephogram

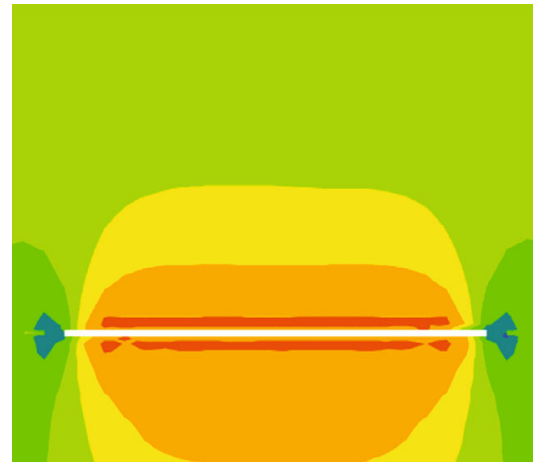
Contour of SZZ
Plane: on
Magfac $=0.000 e+000$
Gradient calculation

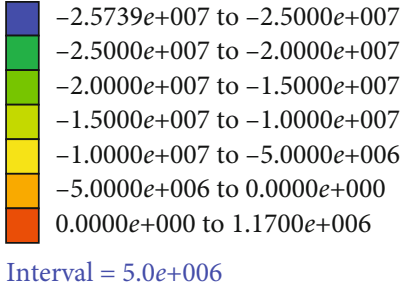

(b) $150 \mathrm{~m}$ vertical stress nephogram

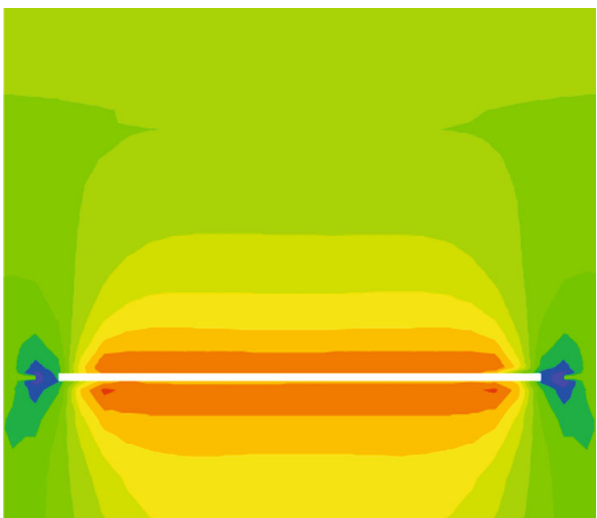

Contour of SZZ

Plane: on

Magfac $=0.000 e+000$

Gradient calculation

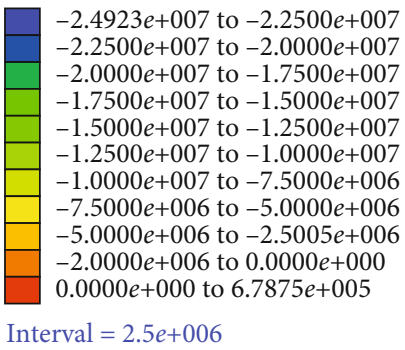

(c) $200 \mathrm{~m}$ vertical stress nephogram
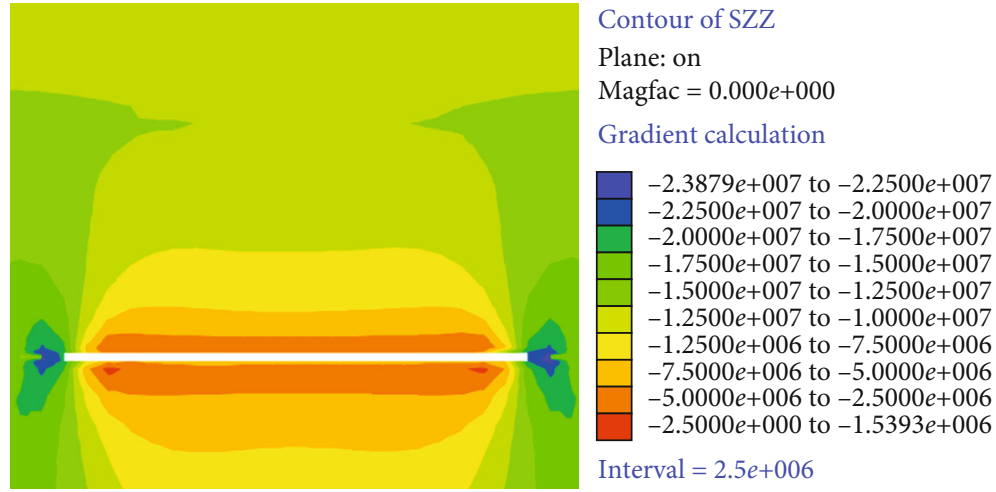

(d) $250 \mathrm{~m}$ vertical stress nephogram

FIGURE 12: Vertical stress nephogram of different stoping stages $(100 \mathrm{~m}, 150 \mathrm{~m}, 200 \mathrm{~m}$, and $250 \mathrm{~m})$ when the length of working face is $200 \mathrm{~m}$. 


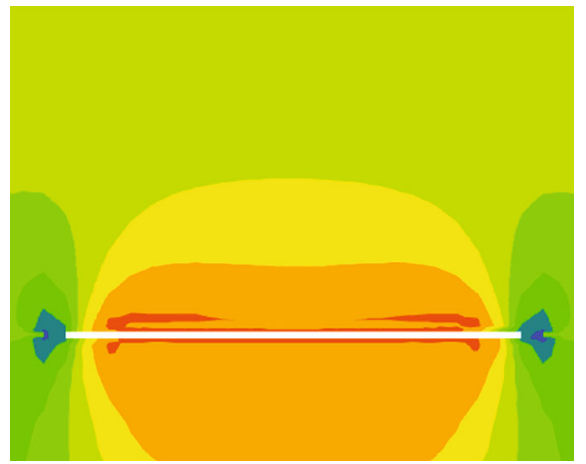

Contour of SZZ

Plane: on

Magfac $=0.000 e+000$

Gradient calculation

$-3.2326 e+007$ to $-3.0000 e+007$ $-3.0000 e+007$ to $-2.5000 e+007$

$-2.5000 e+007$ to $-2.0000 e+007$

$-2.0000 e+007$ to $-1.5000 e+007$

$-1.5000 e+007$ to $-1.0000 e+007$

$-1.0000 e+007$ to $-5.0000 e+006$

$-5.0000 e+006$ to $0.0000 e+006$

$0.0000 e+000$ to $1.2791 e+006$

(a) $100 \mathrm{~m}$ vertical stress nephogram

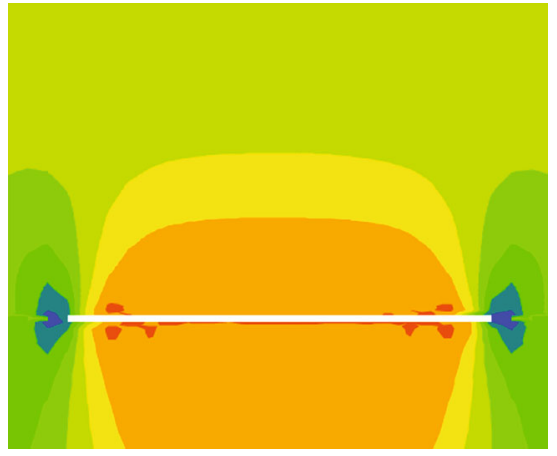

Contour of SZZ

Plane: on

Magfac $=0.000 e+000$

Gradient calculation

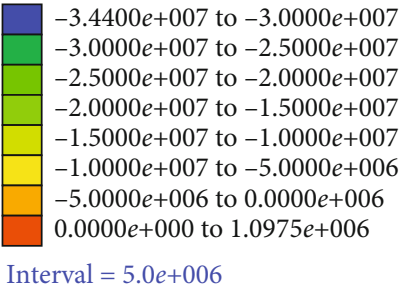

(b) $150 \mathrm{~m}$ vertical stress nephogram

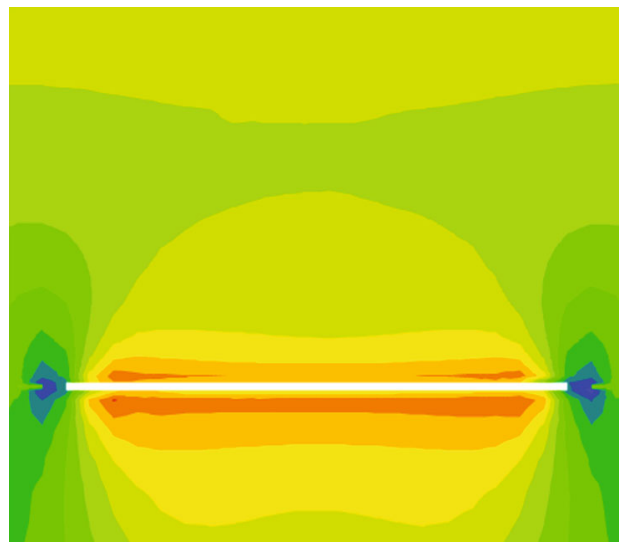

Contour of SZZ

Plane: on

Magfac $=0.000 e+000$

Gradient calculation

(c) $200 \mathrm{~m}$ vertical stress nephogram

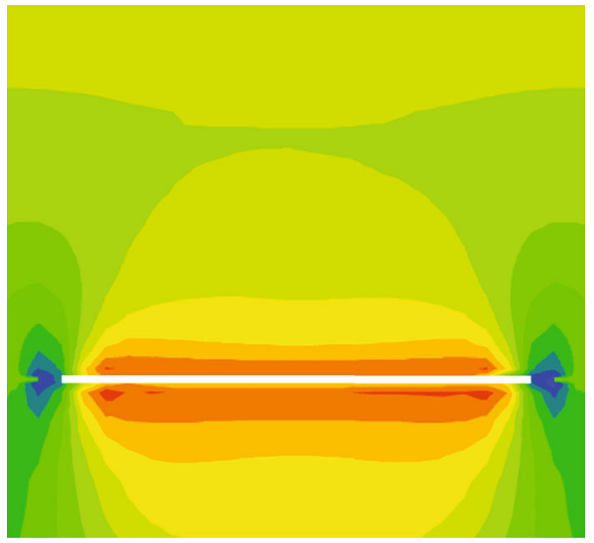

Contour of SZZ

Plane: on

Magfac $=0.000 e+000$

Gradient calculation

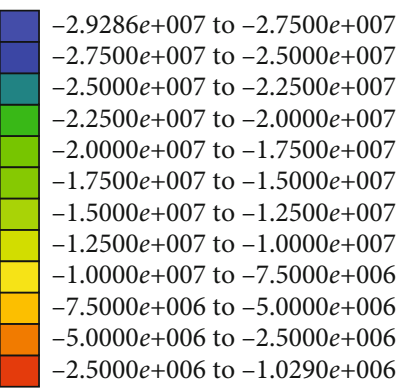

(d) $250 \mathrm{~m}$ vertical stress nephogram

FIGURE 13: Vertical stress nephogram of different stoping stages $(100 \mathrm{~m}, 150 \mathrm{~m}, 200 \mathrm{~m}$, and $250 \mathrm{~m})$ when working face length is $220 \mathrm{~m}$. 


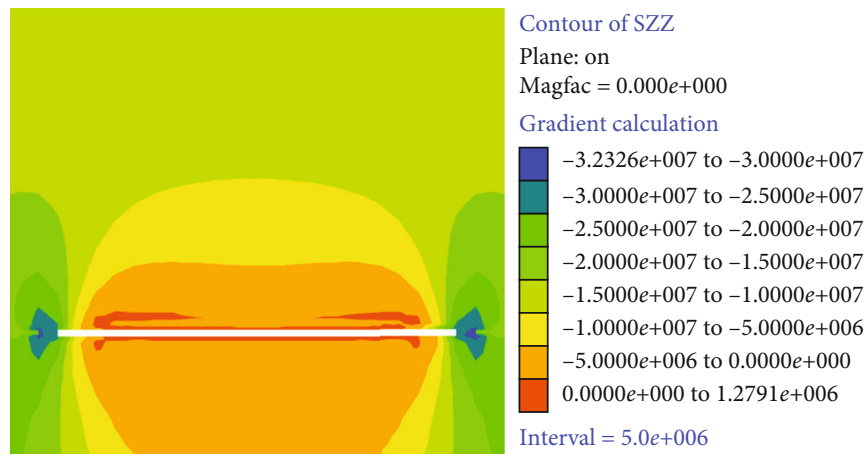

(a) $100 \mathrm{~m}$ vertical stress nephogram

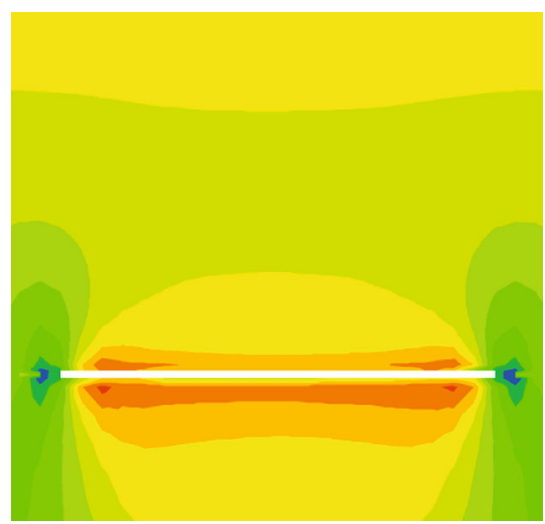

Contour of SZZ

Plane: on

Magfac $=0.000 e+00$

Gradient calculation

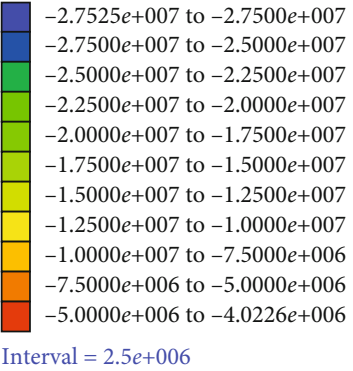

(b) $150 \mathrm{~m}$ vertical stress nephogram
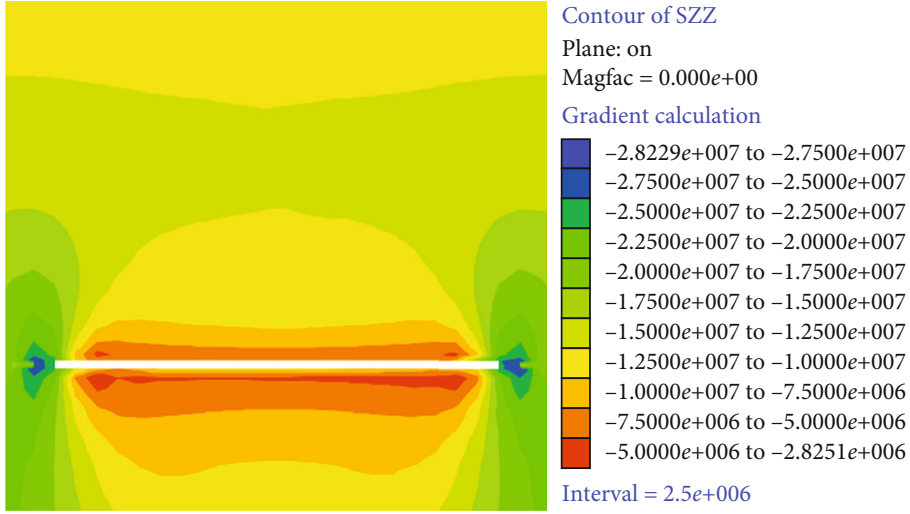

(c) $200 \mathrm{~m}$ vertical stress nephogram
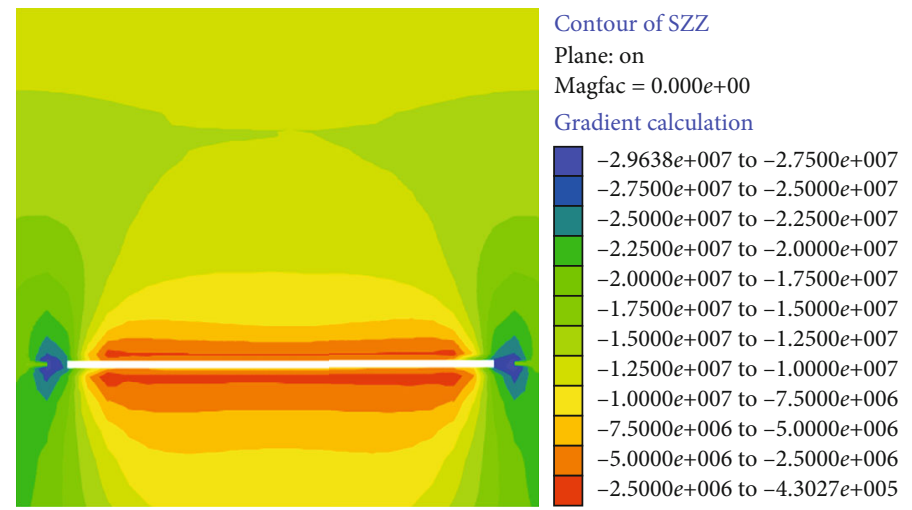

(d) $250 \mathrm{~m}$ vertical stress nephogram

Figure 14: Vertical stress nephogram of different stoping stages $(100 \mathrm{~m}, 150 \mathrm{~m}, 200 \mathrm{~m}$, and $250 \mathrm{~m})$ when working face length is $240 \mathrm{~m}$. 


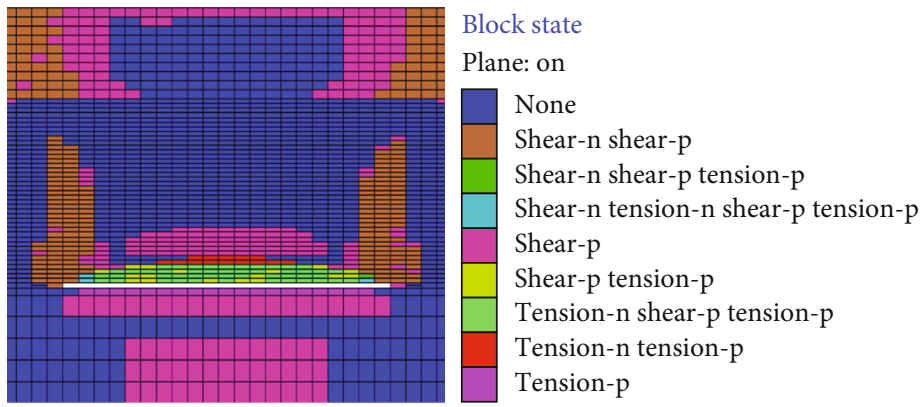

(a) Working face length is $200 \mathrm{~m}$ and advances to $250 \mathrm{~m}$
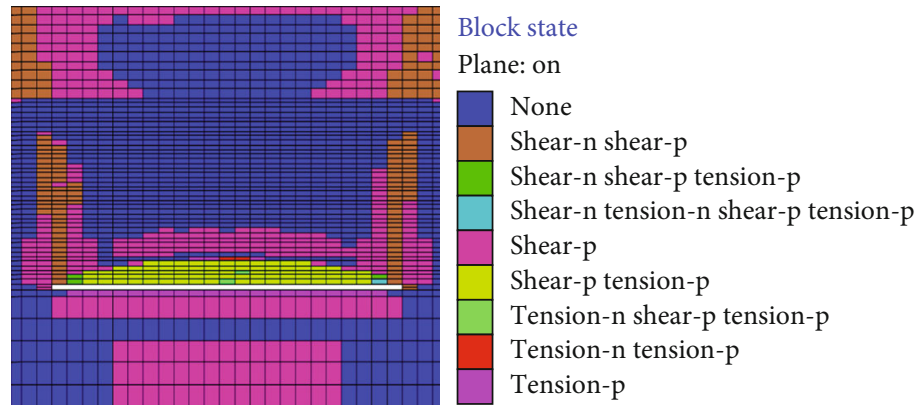

(b) Working face length is $220 \mathrm{~m}$ to $250 \mathrm{~m}$
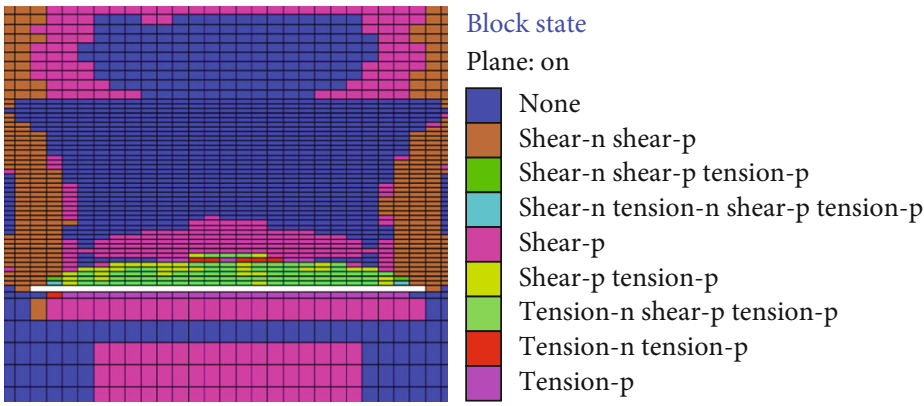

None

Shear-n shear-p

Shear-n shear-p tension- $p$

Shear-n tension- $n$ shear-p tension- $p$

Shear-p

Shear-p tension- $\mathrm{p}$

Tension- $n$ shear- $\mathrm{p}$ tension- $\mathrm{p}$

Tension-n tension-p

Tension-p

(c) Working face length is $240 \mathrm{~m}$ advancing to $250 \mathrm{~m}$

Figure 15: The plastic zone distribution when the working face length is $200 \mathrm{~m}, 220 \mathrm{~m}, 240 \mathrm{~m}$, and pushed to $250 \mathrm{~m}$.

overlying strata in the whole model is obvious. This is because the overlying strata are composed of rock layers of different properties during the deposition process. At the same time, the vertical distance between each layer of rock strata and the working surface is also different, so in the face of the disturbance of underground mining, it will show different characteristics of overlying rock changes. The distribution of strata stress is stress arch, usually in place after the coal for starting cut arch foot, in front of the coal wall stress peak area of stress arch structure of the former arch foot; with the working face advancing, the arch is not fixed but constantly moves forward.

After the end of mining, the horizontal stress distribution in the mined-out area is as follows: the horizontal stress in the mined-out area is larger $20 \sim 40 \mathrm{~m}$ upward, indicating that the influence of stress mining is greater and strong. The change of horizontal stress in the goaf upward $40-80 \mathrm{~m}$ is moderate, and the fluctuation is not large. The horizontal stress from above $80 \mathrm{~m}$ to the surface is small. It is due to the mining of the underground working face, which is far away from the surface of the ground, and the direct roof and basic roof rock layers below have undertaken most of the horizontal deformation. As you can see from the following diagram, there is a significant partitioning phenomenon. It also confirms that the extent of damage to the overlying rock strata caused by mining activities gradually weakens with the increase of distance (Figures 9-11).

3.2.4. Distribution Law of Vertical Stress inside Rock Mass. In the process of advancing the working face, the overburden undergoes the process of "deformation-separationinstability." At the same time, the internal stress of the rock mass also changes accordingly. Because the basic roof is thick and hard and the ability to resist deformation is strong, the duration of each stage is longer. When the working face is advanced to $150 \mathrm{~m}$, the advance influence range of the working face abutment pressure is about $50 \mathrm{~m}$. With the advance of working face, the influence range of leading pressure is also changing, and it has experienced the process of "increasedecrease-increase." After mining, stress concentration appears 


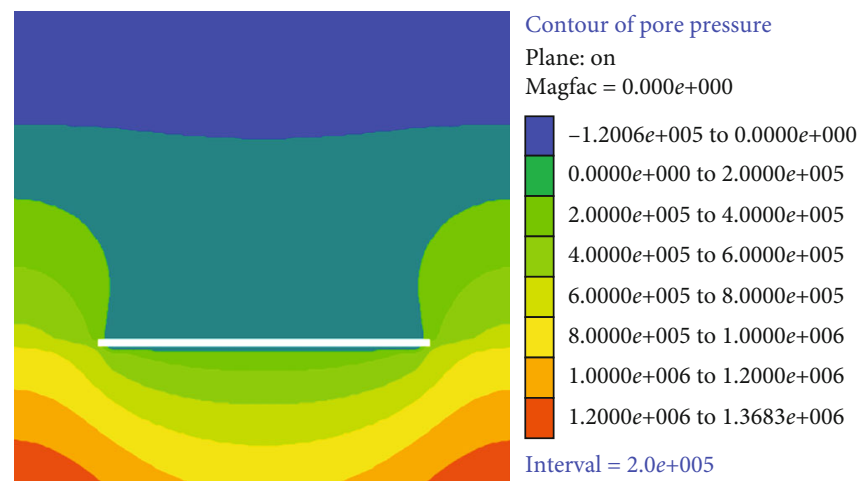

(a) $100 \mathrm{~m}$ advance of working face

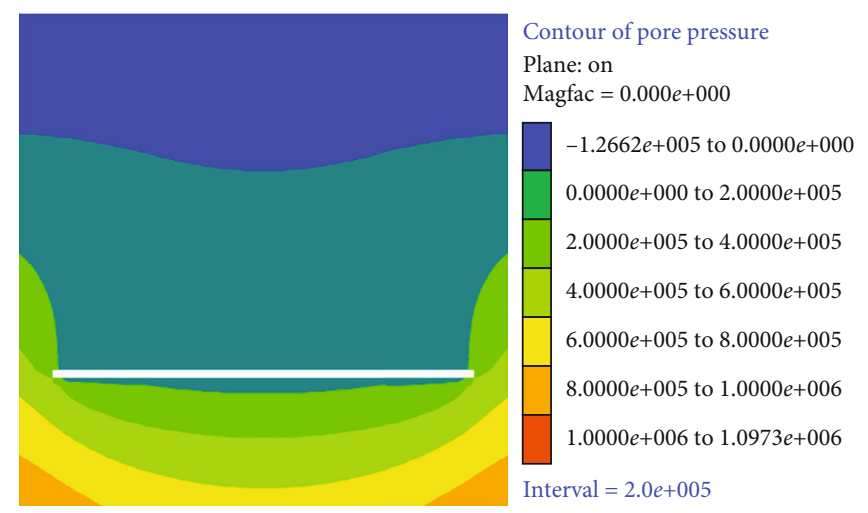

(b) $150 \mathrm{~m}$ advance of working face

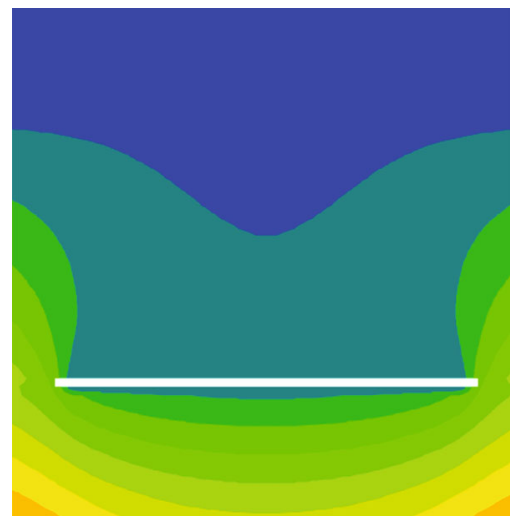

Contour of pore pressure

Plane: on

Magfac $=0.000 e+000$

$-1.4098 e+005$ to $-1.0000 e+005$

$-1.0000 e+005$ to $0.0000 e+000$

$0.0000 e+000$ to $1.0000 e+005$

$1.0000 e+005$ to $2.0000 e+005$

$2.0000 e+005$ to $3.0000 e+005$

$3.0000 e+005$ to $4.0000 e+005$

$4.0000 e+005$ to $5.0000 e+005$

$5.0000 e+005$ to $6.0000 e+005$

$6.0000 e+005$ to $7.0000 e+005$

$7.0000 e+005$ to $8.0000 e+005$

$8.0000 e+005$ to $9.0000 e+005$

$9.0000 e+005$ to $9.0095 e+005$

(c) $200 \mathrm{~m}$ advance of working face
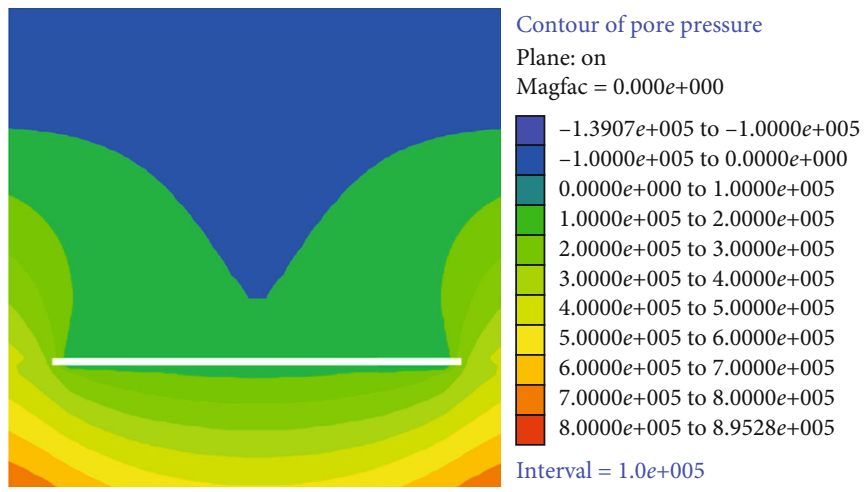

(d) $250 \mathrm{~m}$ advance of working face

FIGURE 16: Cloud diagram of overburden pore water pressure at $250 \mathrm{~m}$ advance of working face advances to $100 \mathrm{~m}, 150 \mathrm{~m}, 200 \mathrm{~m}$, and $250 \mathrm{~m}$. 


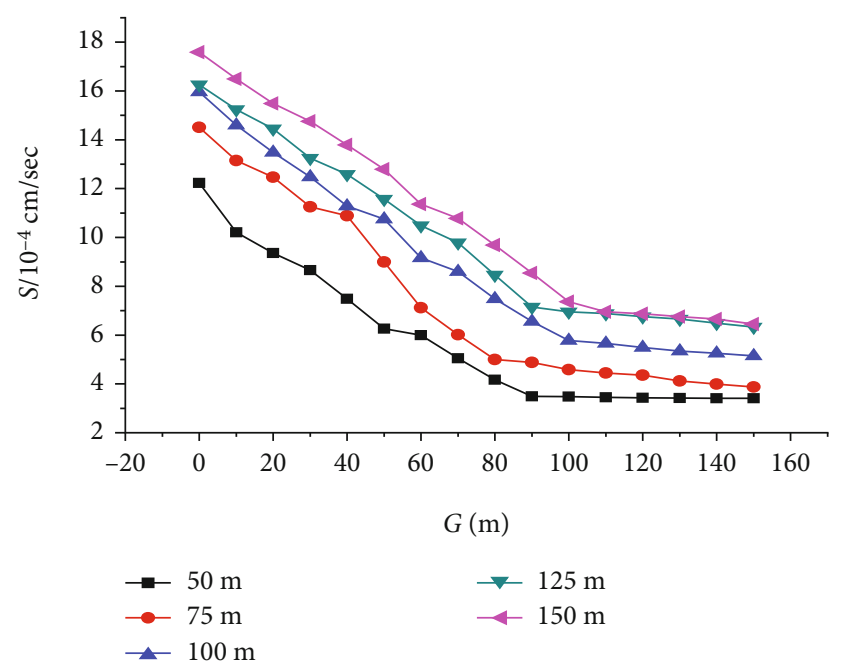

(a)

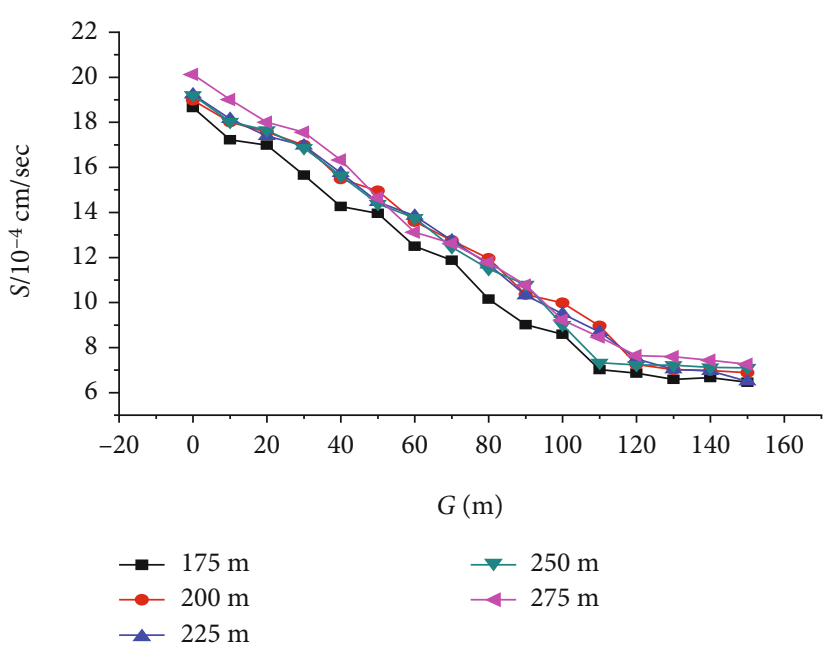

(b)

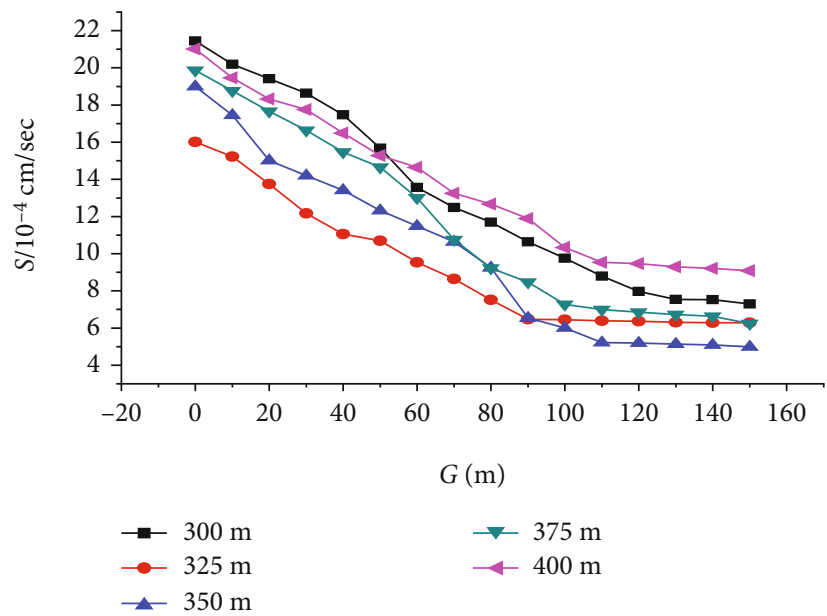

(c)

Figure 17: Comparison of permeability coefficient variation trend of different advancing distances at different working faces.

especially near the top of the coal pillar. The peak depth of the coal wall is $10 \mathrm{~m}$, and the influence range of abutment pressure is about $60 \mathrm{~m}$ in front of the coal wall (Figures 12-14).

\subsubsection{Overburden Failure Status and Plastic Zone} Distribution. In the elastoplastic analysis, when the FLAC program is dealing with the problem, it will judge the stress state of the point according to the Mohr-Coulomb criterion at the same time when calculating the stress and displacement of each element. In the numerical simulation, the following conventions are made: 0 denoted that the rock mass element is still in elastic state; 1 : indicates that the rock mass element is yielding and begins to transition to the plastic state; 2 represents that the rock mass element enters the plastic state; 3 means that the rock mass element has exceeded the uniaxial tensile resistance; 4 represents the yield of rock mass unit and exceeds uniaxial tensile resistance; and 5 indicates that the rock mass element has exceeded the uniaxial tensile resistance. The software uses the existing failure parameters of each unit to integrate, so as to express the failure situation of the whole overburden. The identification of plastic zone is the main basis of the failure state of overburden, as well as the method to judge the distribution law and development height of the water-conducting fracture zone.

It can be seen from the plastic separation diagram that the main failure places are at the top and left and right sides of the model. Under the influence of mining damage, the overburden failure is symmetrically distributed. By comprehensive comparison of various calculation models, different working face lengths lead to different distribution of plastic zone and development height of the water-conducting fracture zone. According to the analysis in Figure 15, when the working face length is $200 \mathrm{~m}$, the maximum height of plastic zone distribution in overlying rock is $48 \mathrm{~m}$. When the working face length of $220 \mathrm{~m}$ strata distribution of plastic zone is in the maximum height of $54 \mathrm{~m}$ and when the working face length of $240 \mathrm{~m}$ strata distribution of plastic zone in the maximum height has communicated the overlying loose bed, the overlying aquifer water inrush occurs; in production practice, it cannot meet the working face length. Under the action of mining seepage, the length of the working face cannot be expanded indefinitely. Once it exceeds a certain value, the 
overburden fissures will communicate with the aquifer and even the surface, causing water inrush accidents. So the working face length of $220 \mathrm{~m}$ is the most reasonable [19-22].

3.2.6. Coupling Analysis of Stress and Seepage of Overlying Rock when Working Face Length is $220 \mathrm{~m}$. Under the influence of mining, the stress of the overlying strata changes, which makes the permeability of the overlying strata change. Therefore, the coupling analysis of stress and seepage is particularly important in engineering applications. The seepage problem of overburden rock caused by mining is mainly to study the law of fluid movement in pores and fissures. Among them, the parameter that best reflects the law of change is the permeability coefficient. The change in permeability coefficient reflects the expansion and closure of pores and fissures. This also explains the overburden from the side. In the law of rock movement, we can analyze the law of seepage through the change of stress, that is, the coupling analysis of stress and seepage.

Here, we take the length of the working face $220 \mathrm{~m}$ as the basis. In the mining geological conditions, we know that there is an aquifer above the bedrock, which will inevitably generate pore water pressure on the surrounding rock formations. The existence of pore water pressure will affect the surrounding rocks. The nature of the pore water will change, and the change of pore water pressure will affect the stress and strain of the rock formation, which will redistribute the stress of the rock formation. In the mining of the working face, the upper and lower ends of the working face and the cut-off are most affected. At this time, the permeability of the rock formation will increase accordingly. As the work surface advances, the stress of the overlying strata of the stope will be redistributed, and the overlying strata will be closed from the original tensile cracks and the permeability at this time The rate gradually decreases until the fissure is closed, the pore water pressure is zero, the working face continues to advance, and the pore water pressure may become negative, because the water-conducting fissure zone may spread to the overlying aquifer, affecting the water level of the aquifer.

According to the simulation, the distribution of pore water pressure reflects the movement of the overlying strata in the process of advancing the working face. The figure shows that the stress distribution at both ends of the working face is concentrated, and a falling funnel appears above the goaf (Figure 16).

According to the numerical simulation results, the change rule of overburden stress under the action of overburden pore water pressure can be obtained, which is expressed by the trend in Figure 17.

Through the above analysis, the movement fracture of the overlying strata in coal mining is the result of the joint action of stress and seepage. The change of stress will change the flow law of fluid accordingly.

\section{Conclusion}

(1) Summing up the relationship between stress and permeability coefficient in the earlier part, these relations are simple and convenient to apply
(2) By using computer numerical simulation technology, the influence of stress on the seepage of fractured rock mass is analyzed. The plastic separation diagram shows that the main areas of failure are above and on the left and right sides of the model. Under the influence of mining damage, the overburden failure is symmetrically distributed. By comprehensive comparison of the calculation models, different working face lengths lead to different distributions of plastic zone and development height of waterconducting fracture zone. Through the comparative analysis of cloud image and trend chart, it is found that the pore water pressure acts on the whole overlying strata and affects the development of fractures, and the change of fracture network also affects the subsidence trend of overlying aquifer, both of which influence each other

(3) The practice shows that the computer numerical simulation analysis of the coupling problem of stress and seepage is intuitive and effective. The application of clear and intuitive diagrams instead of complex theoretical formulas simplifies a lot of work

(4) The above analysis shows that the mining impact of the coal mining area in the Yellow River Basin has led to the destruction of the overlying rock aquifer and the leakage of surface water, affecting the fragile ecological environment of the surface, leading to lack of water for surface vegetation and soil desertification, so the mining area is underway. In ecological restoration, this method can be used to conduct indepth research on the protection and restoration of aquifers, so as to provide a theoretical basis for the ecological protection and high-quality development of the Yellow River Basin

\section{Data Availability}

The data used to support the findings of this study are available from the corresponding author upon request.

\section{Conflicts of Interest}

The authors declare that they have no conflicts of interest to report regarding the present study.

\section{Acknowledgments}

The research was funded by special scientific research plan of Education Department of Shaanxi Province (No. 18JK1046).

\section{References}

[1] R. Singh, P. K. Mandal, A. K. Singh, R. Kumar, J. Maiti, and A. K. Ghosh, "Upshot of strata movement during underground mining of a thick coal seam below hilly terrain," International Journal of Rock Mechanicsand Mining Sciences, vol. 45, no. 1, pp. 29-46, 2008.

[2] Q. Wang, Z. Jiang, B. Jiang, H. Gao, Y. Huang, and P. Zhang, "Research on an automatic roadway formation method in 
deep mining areas by roof cutting with high-strength boltgrouting," International Journal of Rock Mechanics and Mining Sciences, vol. 128, 2020.

[3] Q. Wang, Y. Wang, M. C. He et al., "Experimental research and application of automatically formed roadway without advance tunneling," Tunnelling and Underground Space Technology., vol. 114, no. 3, 2021.

[4] A. Li, F. Dai, Y. Liu, H. B. Du, and R. C. Jiang, "Dynamic stability evaluation of underground cavern sidewalls against flexural toppling considering excavation-induced damage," Tunnelling and Underground Space Technology, vol. 112, 2021.

[5] R. D. Miller, D. W. Steeples, and L. Schulte, "Shallow reflection study of salt dissolution well field meal," Mining Engineering, vol. $45,1993$.

[6] Q. X. Meng, W. Y. Xu, H. L. Wang, X. Y. Zhuang, W. C. Xie, and T. Rabczuk, "DigiSim - an open source software package for heterogeneous material modeling based on digital image processing," Advances in Engineering Software, vol. 148, 2020.

[7] H. Qingxiang, Roof Structure and Strata Control of Longwall Mining in Shallow Coal Seam, China University of Mining and Technology Press, Xuzhou, 2000.

[8] Q. Minggao, M. Xiexing, and X. Jialin, Key Strata Theory of Rock Strata Control, China University of Mining and Technology Press, Xuzhou, 2000.

[9] M. Bai and D. Elsworth, "Modeling of subsidence and stress dependent hydraulic conductivity for intact and fractured porous media," Rock Mechanics \& Rock Engineering, vol. 27, no. 4, pp. 235-251, 1994.

[10] Z. Jincai, L. Tianquan, and Z. Yuzhuo, "Research on the permeability characteristics of fractured rock mass," Journal of China Coal Society, vol. 22, no. 5, pp. 481-485, 1997.

[11] L. Shiwei, "Simulation of water-retaining mining in shallow coal seam with thick soil layer," Journal of Liaoning Technical University, vol. 32, no. 6, pp. 741-744, 2013.

[12] L. Shiwei, "Numerical simulation of water conducting fracture zone $\mathrm{H} 8$ of 2301 working face in Yuyang coal mine," Chinese Journal of Production Safety Science and Technology, vol. 9, no. 3, pp. 46-50, 2013.

[13] L. Shiwei, "Study on water inrush mechanism of roof in shallow coal seam with thin bedrock," Mining Safety and Environmental Protection, vol. 40, no. 3, pp. 21-24, 2013.

[14] L. Zhengqiu and B. Shihua, A Brief Course of Material Mechanics, Higher Education Press, Beijing, 2000.

[15] T. Min, "Research on the development height of mininginduced rock mass fracture in Panxie mining area," Journal of China Coal Society, vol. 29, no. 6, pp. 641-645, 2004.

[16] L. Shiwei, "Study on overburden failure of coal seam mining under coupling of stress and see page," Journal of Hulun Buir College, vol. 25, no. 6, 2017.

[17] X. Kong, Advanced Seepage Mechanics, University of Science and Technology of China Press, Hefei, 1999.

[18] X. Zhang, Z. Xia, C. Yao, J. Yang, and M. Yang, "Experimental study on seepage properties of postpeak fractured rocks under cyclic loading-unloading confining stress and axial stress," Geofluids, vol. 2021, 12 pages, 2021.

[19] L. Wen, Y. Li, and J. Chai, "Numerical simulation and performance assessment of seepage control effect on the fractured surrounding rock of the Wunonglong underground powerhouse," International Journal of Geomechanics, vol. 20, no. 12, 2020.
[20] W. B. Sun, Y. C. Xue, L. M. Yin, and J. Zhang, "Experimental study on seepage characteristics of large size rock specimens under three-dimensional stress," Geomechanics and Engineering, vol. 18, 2019.

[21] L. Zhou, K. Su, H. Wu, and C. Shi, "Numerical investigation of grouting of rock mass with fracture propagation using cohesive finite elements," International Journal of Geomechanics, vol. 18, no. 7, 2018.

[22] T. Yang, H. Y. Liu, and C. A. Tang, "Scale effect in macroscopic permeability of jointed rock mass using a coupled stressdamage-flow method," Engineering Geology, vol. 228, pp. 121-136, 2017. 